\title{
NEW FORMS OF WORK IN THE DIGITAL ECONOMY
}

2016 MINISTERIAL MEETING ON THE DIGITAL ECONOMY

TECHNICAL REPORT 


\section{FOREWORD}

This report was prepared as a contribution to the background report of Panel 4.1 "New Market and New Jobs" of the OECD Ministerial Meeting on the Digital Economy, 21-23 June 2016, Cancún (Mexico). It provides new evidence on the development of online platform markets, discusses patterns, opportunities and challenges of new forms of work in platform service markets, presents analysis of non-standard work in OECD countries, and identifies policy issues related to new forms of work.

This report was prepared by David Gierten, with inputs from Vincenzo Spiezia, OECD, for the Working Party on Measurement and Analysis of the Digital Economy (MADE). Airbnb, Youpijob and Freelancer shared data with the OECD for this report and Uber commented on the paper's use of publically available data on Uber.

The report was approved and declassified by the Committee on Digital Economy Policies (CDEP) on 13 May 2016 and prepared for publication by the OECD Secretariat.

Note to Delegations:

This document is also available on OLIS under reference code: DSTI/ICCP/IIS(2015)13/FINAL

This document and any map included herein are without prejudice to the status of or sovereignty over any territory, to the delimitation of international frontiers and boundaries and to the name of any territory, city or area.

The statistical data for Israel are supplied by and under the responsibility of the relevant Israeli authorities. The use of such data by the OECD is without prejudice to the status of the Golan Heights, East Jerusalem and Israeli settlements in the West Bank under the terms of international law.

\section{(C) OECD 2016}

You can copy, download or print OECD content for your own use, and you can include excerpts from OECD publications, databases and multimedia products in your own documents, presentations, blogs, websites and teaching materials, provided that suitable acknowledgment of OECD as source and copyright owner is given. All requests for commercial use and translation rights should be submitted to rights@oecd.org. 
TABLE OF CONTENTS

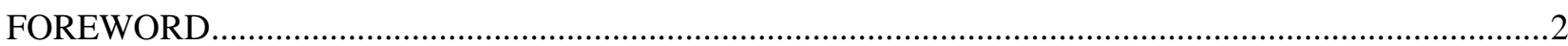

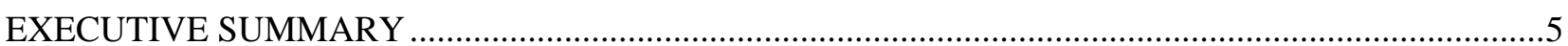

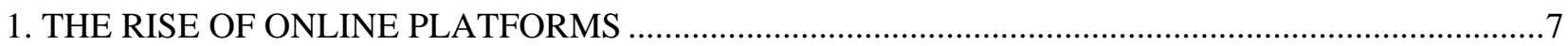

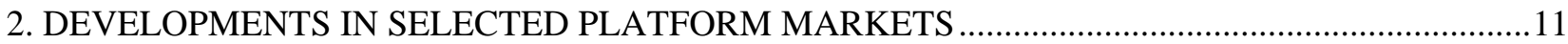

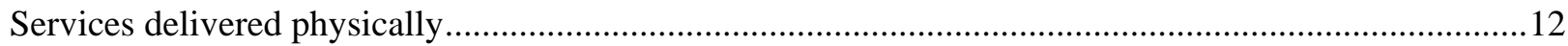

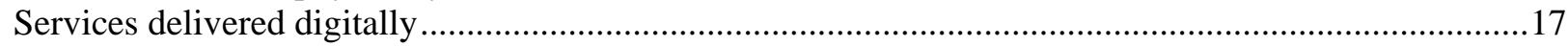

Patterns of work and income............................................................................................................

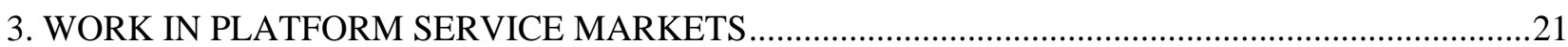

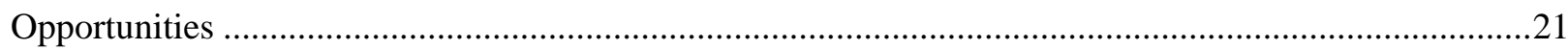

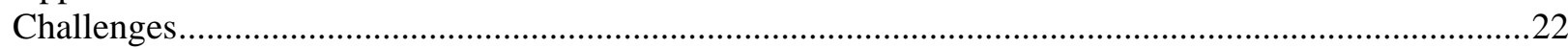

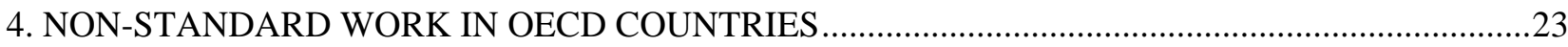

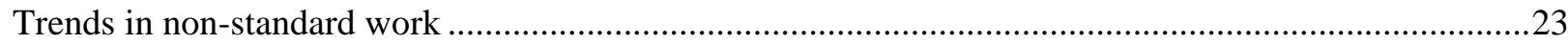

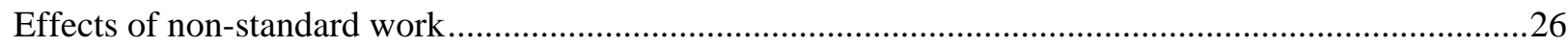

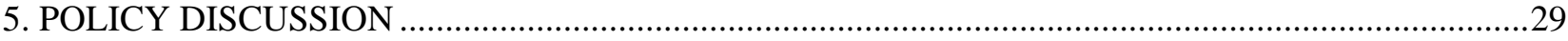

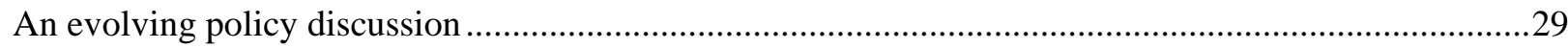

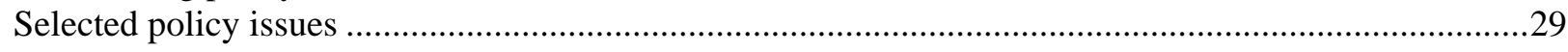

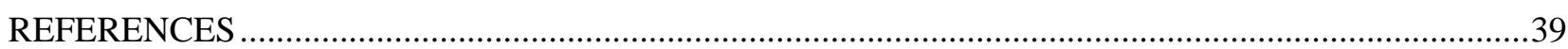

\section{Tables}

Table 1. Top 15 public Internet companies by market capitalisation in 1995 and 2015 ......................7

Table 2. Duration of Airbnb stays in major Airbnb markets ...............................................................15

Table 3. Drivers, hours worked, and revenues in selected Uber markets ..........................................16

Table 4. Job categories and average job value by category on Youpijob, 2012-15 ...........................16

Table 5. Job categories on Freelancer and Upwork .................................................................18

Table 6. Fastest growing jobs and skills on Upwork based on earnings, 2014 ................................19

Table 7. Top 10 employer and provider countries on Upwork, 2014 .............................................19

Table 8. Participation and revenue in platform markets in the US ...................................................20

Table 9. Opportunities and challenges of new forms of work and other non-standard work ...............36

\section{Figures}

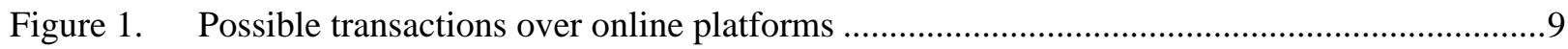

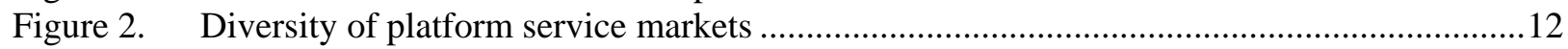

Figure 3. Airbnb hosts and nights hosted in the United States and major European markets ...............13

Figure 4. Types of accommodation booked in major Airbnb markets ..............................................14

Figure 5. Average annual revenue from Airbnb and average nightly prices ....................................15

Figure 6. Demand and supply of Youpijob services in French cities ............................................17

Figure 7. Registered users on selected platforms .........................................................................18 
Figure 8. Non-standard work as a share of total employment, 2013

Figure 9. Employment growth by type of employment, 2007-2013 ................................................24

Figure 10. Self-employed workers and non-employer establishments in the United States ...............25

Figure 11. Reason for having a contract of limited duration ....................................................26

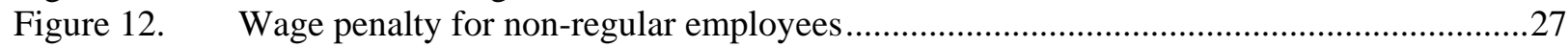

Figure 13. Temporary workers and employer-sponsored training .................................................27

Figure 14. Probability for transitioning from employment to unemployment in one year ................28

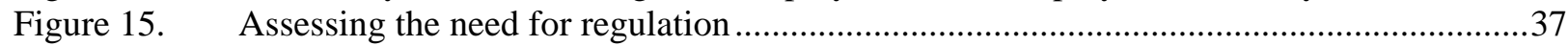

\section{Boxes}

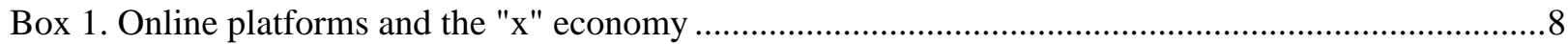

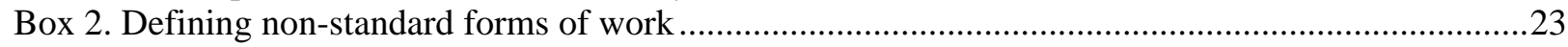

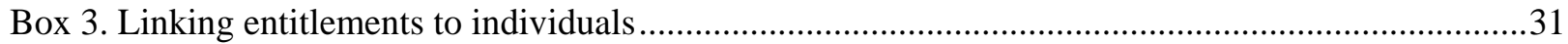

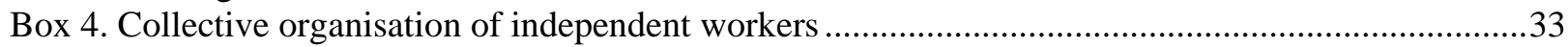

Box 5. Co-operation between platforms and regulators ..........................................................................34 


\section{EXECUTIVE SUMMARY}

Many markets are increasingly becoming digital. This transformation is often driven by online platforms that facilitate interaction and (re-)intermediate transactions, partly or fully online, by matching demand and supply of goods (e-commerce), services (the "x"-economy) and information (search, social networks, content). This paper examines how online platforms affect production and in particular the organisation of work (section 1); provides new data on developments in selected platform markets (section 2); discusses the work and income opportunities created in these markets and related challenges (section 3); presents OECD analysis of non-standard work (NSW) (section 4); and identifies policy issues related to work in platform service markets (PW), including measurement needs and approaches to collect better data for further analysis of these topics (section 5).

By 2015, operators of online platforms for information, goods and services had risen to almost fully dominate the top 15 of the world's largest Internet based companies by market capitalisation. Online platforms not only scale fast while gaining little mass through matching several networks in two- or multisided markets, which fuels high valuation of the operating companies; they also lower transaction costs to a point at which individuals can compete directly with firms, in particular in service markets. This paper focuses on platform service markets, which among different online platform markets seem to have created the most notable work and income opportunities for individuals to date. There are limits for individuals to compete with firms, but individually provided platform-based services could gain larger shares in more markets that are traditionally dominated by firms.

Online platforms have grown exponentially in several service markets over the past decade, driven by demand for a range of services that can often be provided by individuals. This range includes services delivered physically (mostly local) like accommodation, transportation, handyman or personal services, and services delivered digitally (mostly over the Internet), from data entry and administrative support over graphic design and coding to legal and business consulting. To a large extent, these services are provided by individuals who monetise personal assets, skills and time. How these individuals work to provide such services and what revenue the latter bring differs across markets, but some common patterns can be identified and are discussed in this paper as both the opportunities and the challenges they may present.

When, where, and how individuals work in platform service markets tends to differ from what is known as standard work (full-time permanent employment). By lowering entry barriers to sell directly to final clients, online platforms facilitate individual service provision by individuals, who in many cases work on a temporary or irregular basis, often part-time, and frequently in combination with other activities and income sources. While currently available data does not provide a comprehensive picture on precise working patterns in platform markets, and while measurement of such work has to improve, this paper presents evidence on NSW in OECD countries, which helps situating PW in the context of larger trends in OECD labour markets.

NSW is well established across the OECD and analysis of such work provides relevant insights for the discussion of PW. The OECD definition of NSW excludes full-time permanent employment and includes self-employed, temporary, and part-time workers, all of which have existed long before the rise of platform service markets. Given the significant and rising average share of NSW in the workforces of (29) OECD countries (33\%), today's PW is likely to not account for much NSW nor to be a key driver of its growing share in many countries. However, some PW seems to be similar to and might partly overlap with NSW and findings on the latter can provide relevant insights for such forms of PW. Compared to full-time permanent employment, the OECD finds that non-standard work is likely to go along with wage penalties, lower chances to receive employer-sponsored training, and a higher risk for workers to transition into unemployment. 
While the development of PW is still in an early stage and better data is needed on both PW and NSW, several policy issues have gained attention and are discussed in this paper. Selected issues include those related to the status of service providers in platform markets, to multi-jobbing, to provider competition and online reputation, to fundamental principles and rights of workers, to tasks and skills, and to privacy. Furthermore, the paper discusses the potential role of platforms as regulators and enforcers and criteria for assessing the appropriateness of regulatory frameworks in light of new practices in platform markets. More work is needed to go beyond the initial spotlight this paper sheds on selected issues based on the limited data and experience available to date. A priority for further work should be better data collection, including through closer co-operation between platforms and other actors.

Other key areas related to platform markets that require work include: i) effects of online platforms on macro economic indicators, productivity, the environment, inequality, and well-being, ii) competition among platforms, competition between platforms and more traditional players, as well as competition among providers within platform markets, and iii) consumer protection and privacy related issues in the context of platforms that create or enter markets. Much as for issues related to PW, in order for any of these topics to be treated adequately, a priority should be more and better data collection. 


\section{THE RISE OF ONLINE PLATFORMS}

The Internet made it easier than ever before to match demand and supply in real-time both locally and globally. Today's Internet is used by a diversity of online platforms that operate at the core of evolving digital ecosystems and provide marketplaces for goods, services and information, delivered both physically and digitally. Many such platforms have emerged over the past 20 years and are operated by fast growing companies. A comparison between the top 15 Internet based companies by market capitalisation in 1995 with those in 2015 shows that the main players used to be Internet Service Providers (ISPs), media and hard- or software companies, whereas today most are platform operators (Table 1). Six of the 13 platforms in 2015 are marketplaces for goods or services (e-commerce), 5 match information demand and supply (search, social network, advertising), and among the total, 5 match individuals with peers (P2P), rather than business with business (B2B) or business with consumers (B2C). Several platforms combine more than two markets and enable different types of transactions on the same platform, including P2P and B2C, e.g. Facebook. Apple and Salesforce are somewhat exceptions to the 2015 list, although Apple also operates successful platforms (iTunes and App Store) that did not exist in 1995.

Table 1. Top 15 public Internet companies by market capitalisation in 1995 and 2015

\begin{tabular}{|l|l|l|l|l|l|l|}
\hline & $\begin{array}{l}\mathbf{1 9 9 5} \\
\text { December }\end{array}$ & $\begin{array}{l}\text { Main product or } \\
\text { activity }\end{array}$ & $\begin{array}{l}\text { USD } \\
\text { bn }\end{array}$ & $\begin{array}{l}\text { 2015* } \\
\text { May }\end{array}$ & $\begin{array}{l}\text { Main product or } \\
\text { activity }\end{array}$ & $\begin{array}{l}\text { USD } \\
\text { bn }\end{array}$ \\
\hline 1 & Netscape & Software & 5.42 & Apple & Hardware, services & 763.57 \\
\hline 2 & Apple & Hardware & 3.92 & Google & Information (search) & 373.44 \\
\hline 3 & Axel Springer & Media, publishing & 2.32 & Alibaba & Goods (e-com) & 232.76 \\
\hline 4 & RentPath & Media, rental & 1.56 & Facebook & Information (social, P2P) & 226.01 \\
\hline 5 & Web.com & Web services & 0.98 & Amazon.com & Goods (e-com) & 199.14 \\
\hline 6 & PSINet & ISP & 0.74 & Tencent & Information (social, P2P) & 190.11 \\
\hline 7 & Netcom On-Line & ISP & 0.40 & eBay & Goods (e-com, P2P) & 72.55 \\
\hline 8 & IAC/ Interactive & Media & 0.33 & Baidu China & Information (search) & 71.58 \\
\hline 9 & Copart & Vehicle auctions & 0.33 & Priceline Group & Services & 62.65 \\
\hline 10 & Wavo Corporation & Media & 0.20 & Uber & Services (P2P) & 51.00 \\
\hline 11 & iStar Internet & ISP & 0.17 & Salesforce.com & Services & 49.17 \\
\hline 12 & Firefox Communications & ISP & 0.16 & JD.com & Goods (e-com) & 47.71 \\
\hline 13 & Storage Computer Corp. & Storage software & 0.10 & Yahoo! & Information (search) & 40.81 \\
\hline 14 & Live Microsystems & Hard- and Software & 0.09 & Netflix & Services (media) & 37.70 \\
\hline 15 & iLive & Media & 0.06 & Airbnb & Services (P2P) & 25.00 \\
\hline & & & $\mathbf{1 7}$ & & & $\mathbf{2 , 4 4 3}$ \\
\hline
\end{tabular}

Note: *Uber and Airbnb are not publically traded companies and their market valuation is based on estimations. They are replacing LinkedIn (14) and Twitter (15) from the original list compiled by the source.

Source: based on KPCB, 2015; Fortune, 2015a.

Beyond the changed composition of these 15 companies, their value by market capitalisation (current dollars) has multiplied 144 times over 20 years and their activities are increasingly divers. In contrast to a traditional firm, the valuation of a platform operator often does not primarily reflect its sales, but the value of the networks - individuals or firms - it matches, their transactions, and the data they generate. As market providers online platforms operate in many different areas: alone, the ones listed above are active in accommodation, advertising, communication, content, retail, transportation, and travel. While in earlier 
days of the Internet markets for digital (or digitisable) data, information, content, and services were most prone to be created or to be moved to the Internet by online platforms, in more recent years the latter have created or tapped into markets for physical services such as transportation (Uber), accommodation (Airbnb) and others (TaskRabbit), by allowing such services to be transacted partly over the Internet.

\section{Box 1. Online platforms and the "x" economy}

The scope of the term "online platforms" used in this paper can include more than "Internet platforms", but is defined narrower than "digital platforms", the latter of which could include, for example, operating systems, which are beyond the scope of the paper. Over-the-top (OTT) service providers are also often called (Internet/online/digital) platforms and only some types of OTT-2 platforms (see "OTT-2" definition of the Body of European Regulators for Electronic Communications) fall into the scope of this paper. The term "platform" is used equivalent to "online platform". The firms that operate online platforms, also called digital matching firms or online intermediaries, are referred to as "platform operators".

Following established online platforms that administer markets for goods (Amazon, e-bay) and information (Google, Facebook), platform service markets like Uber, Airbnb or Freelancer have reached significant scale only recently. Transactions in these markets can involve peers only (P2P), businesses and consumers (B2C) or businesses only (B2B). Many sellers are individuals that monetise assets such as homes, cars, money, labour and skills in order to provide services like accommodation (Airbnb), transportation (Uber), handyman or personal services (TaskRabbit, Youpijob, Care), delivered physically; or services like clickwork (Clickworker), peer-lending and crowdfunding (Lending Club, Kickstarter, Angellist), administrative support, coding, graphic design (Upwork, Freelancer), or legal and business consulting (Upcounsel, MBA\&Company), delivered digitally and mostly over the Internet.

A number of different notions have emerged to name the respective platform service markets, each of which usually characterises one specific aspect that may differentiate such markets from traditional ones, for example their potential to involve "collaboration", "sharing" or the delivery of services "on-demand". These terms are in turn used to denominate an " $x$ " economy, i.e. a sharing- a collaborative- or an on-demand economy. This paper uses none of the " $\mathrm{x}$ " economy terms, given that its focus is not on any one of these aspects in particular. The term "platform economy", often used to refer to a larger range of platform markets, is too broad for this paper, which instead refers to (online) platform markets and more specifically to platform service markets, given that it finds these markets to create notable work and income opportunities, many of which can be characterised as new forms of work.

Platforms can match demand and supply of several markets at once, exploit the effects of combined networks, and shape market conditions. Typical examples for multi-sided platform markets are Google or Facebook, both of which match information demand and supply, and at the same time advertisement "demand" and supply. By centralising several markets and networks on one platform, the platform operator gains a powerful position in the middle, can exploit network effects within and across different markets, and shape the conditions of these markets to function. For example, search and social network platforms cross-subsidise the "free" services they provide in one market with revenue from another market, notably from advertisers. Although many of the more recently emerged platforms like Airbnb or Uber focus on two markets only, they also benefit from strong network effects on both sides of their platform and use their power to shape the market, including prices in the case of Uber. Once a platform's networks have reached critical size, network effects protect the platform's position, possibly market dominance, by functioning as barriers to entry for other firms or platforms. Network effects also tend to lock in customers that would be worse off when switching to a competing platform with smaller networks, given that the latter is unlikely to match the offer of the larger platform, for example in terms product choice, price, or quality of service.

Another explanation for the success of platforms is their ability to lower transaction costs. With his essays on The Nature of the Firm (1937) and The Problem of Social Cost (1960), Ronald Coase was among the first economists who discussed the costs of market transactions, which he saw as one of the main reasons for firms to exist. The term "transaction costs" commonly refers to different types of costs occurring in markets, in addition to the production price of a good or service, notably the cost of: i) finding 
reliable information on the desired product, ii) bargaining the price and contract, and iii) monitoring and enforcing transactions. By bundling complementary assets and activities, firms "supersede the price mechanism" of markets and create value (Coase, 1937). While firms therewith create firm-market boundaries, platforms can lower transaction costs in markets without (re-)creating firm-market boundaries and possibly contribute to dissolving the latter. Where a firm "rather makes than buys" when information and input prices are uncertain, platforms facilitate buying rather than making by providing more information, e.g. on price, products and providers, than was available in traditional markets. In their supply side markets, platforms facilitate the entry of both firm and non-firm actors, including non-professional individuals or peers (Figure 1).

Figure 1. Possible transactions over online platforms

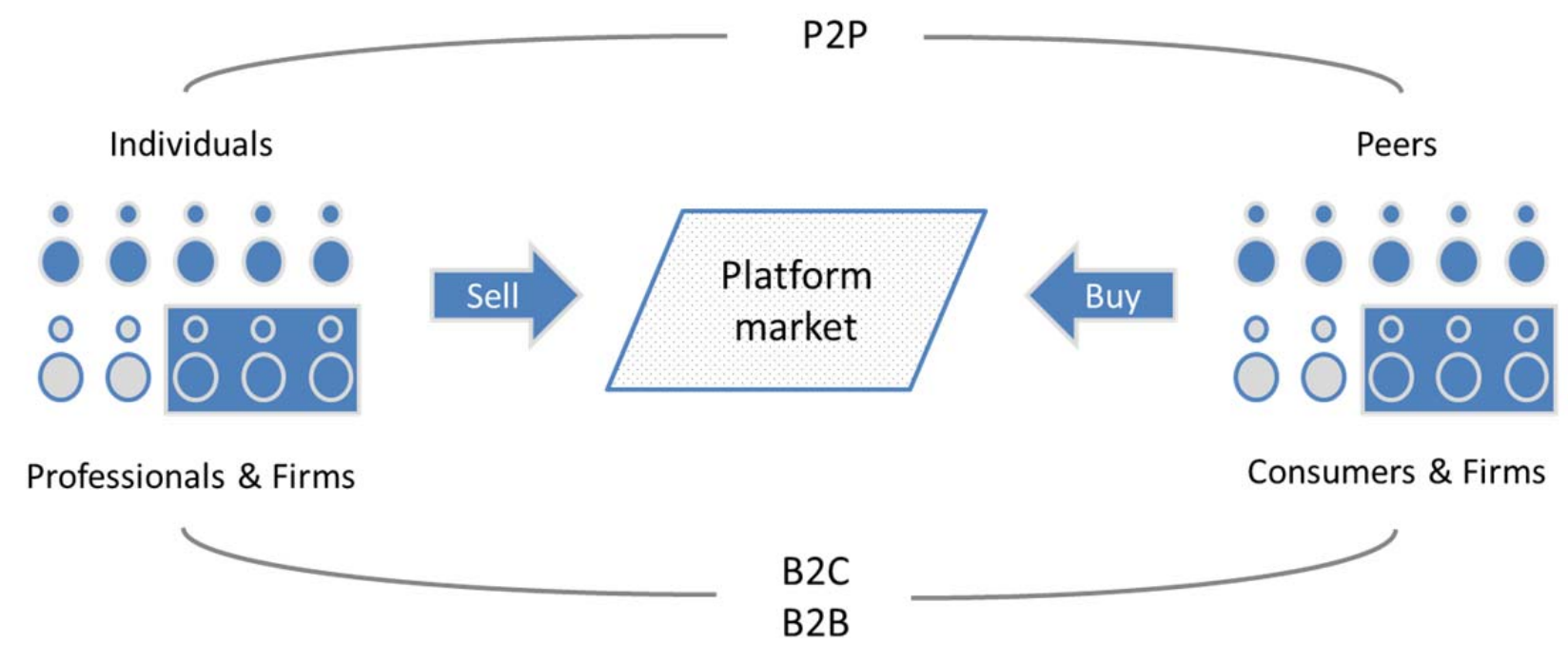

Source: OECD, 2016

By lowering transaction costs, platforms increase the efficiency of markets, but not necessarily the efficiency of production in these markets. Firms bundle complementary assets and activities, including in space, create scale and enable efficient production. Platforms also create scale; however, they scale markets, not production, and rather enable efficient transactions. Contrary to the firms' bundling of production assets, platforms tend to disaggregate production, which in turn is carried out by small dispersed producers, often individuals, and bundle outputs of the latter in online markets. Also in contrast to firms, which gain mass when scaling up production, platforms scale markets without gaining much mass (Brynjolfsson, 2008). While asset light platforms can administer markets globally, they do not necessarily make producers in these markets, e.g. service providers, more efficient. For example, it remains to be understood whether 30 Airbnb hosts, each of which provides one night of accommodation, produces the service more efficiently than one hotel with 30 rooms. While in some respect, platform markets might increase efficiencies, such as by enabling potentially higher capacity utilisation of assets, small scale production might in turn reduce efficiencies.

Platforms lower barriers for small providers to enter markets, however, the means of individuals to compete with firms are limited. In addition to providing an online market place, platforms usually provide a range of tools that facilitate sales and thus market entry for small players, often individuals. The latter can compete with firms in some, but not in all markets. Simple services delivered physically, such as driving, do not necessarily require firm organisation and can be provided competitively by individuals. However, individuals are unlikely to be competitive on products that are produced more efficiently at scale 
or are too complex. In particular for physical products, both scale effects and complexity limit individuals' potential to compete. In the production of digital products individuals might be able to compensate for some scale effects by leveraging digital technologies and data analytics; however, firms are likely to be still superior in generating solutions for complex problems by combining a range of approaches, tools and skills that one individual is unlikely to develop, combine and use all by itself.

Despite these limitations, individuals might gain significant shares in some traditionally firm-dominated service markets by leveraging digital technologies and by trading over online platforms. Potentially concerned markets include, for example, transportation, retail, financial and food services, all of which are traditionally dominated by large corporate employers in many countries (Davis, 2015). Markets for higher skilled services might also be concerned (Miller, 2012). An increase of platform-based transactions in such markets, among peers or between professionals and consumers, at the expense of traditional B2C transactions, would reduce firms' shares, and respectively firm-based employment, to the benefit of individuals providing similar services independently. At a theoretical constant market size, such a redistribution of market shares would entail a gradual shift in the respective labour market from employee-firm relationships to more self-employed or other forms of non-standard work. To date, the available data is insufficient to confirm or to deny such a trend and more evidence is needed to understand whether and to what extent new entrants in concerned markets substitute existing supply or might actually increase the overall market size by serving previously underserved demand. The data presented in the next section shows developments in selected platform markets and helps identify patterns of work and income in these markets. 


\section{DEVELOPMENTS IN SELECTED PLATFORM MARKETS}

In many countries, the amount of individuals that participate in platform markets has grown significantly over recent years. While only few public agencies have started measuring this development, several surveys provide an indication of recent trends. For example, $72 \%$ of adults in the United States (US) are found to have used at least 1 of 11 different "shared and on-demand services" and $17 \%$ of Europeans have used the services of "collaborative platforms" at least once (Pew, 2016; EC, 2016); of those Europeans 32\% (5\% in total) also provided services; in Sweden and in the United Kingdom (UK) $12 \%$ and $11 \%$ of adults respectively say to have worked via a "sharing economy" platform (EC, 2016; Uni Europa, 2016; University of Hertfordshire, 2016). The number of individuals with platform-based revenues in the US has increased tenfold from October 2012 to $1 \%$ of adults in September 2015, and the US on-demand labour market is estimated to grow by over 18\% per year until 2020 (JPM, 2016; Intuit, 2015). These figures result from the use of different methodologies and cannot be directly compared; however, they indicate an order of magnitude of individuals' current and growing participation in platform markets.

The size of platform markets can be estimated, at least roughly, based on transaction volumes. Reliable data on transactions over online platforms is still scarce, but unconfirmed estimates for single platforms can give an indication of market sizes. For example, Airbnb, founded in 2008, estimated in mid2015 to make USD 900 million in revenue by the end of that year, which would mean it operated a market of around USD 7.5 billion in 2015, given that it takes a share of around 9\% on average per transaction, 3\% from hosts and 6-12\% from guests (Fortune, 2015b). Uber, founded in 2009, estimated that its global bookings will amount to about USD 10 billion in 2015, 20\% of which it takes on average for its matching service (Reuters, 2015). These figures were presented by the respective companies to investors, so they might be overestimations. A 2015 report from Staffing Industry estimated more conservatively that in 2014 a total of USD 2.8 - 3.7 billion was spent for services delivered both physically, such the ones sold via Airbnb, Uber or TaskRabbit, as well as digitally, such as those traded on Upwork or Freelancer.

Platforms are not only growing in size, but are emerging in many different service markets. Figure 2 categorises a range of platforms service markets based on several criteria that distinguish between services that i) are being delivered digitally (i.e. tradables, upper half) versus being delivered physically (i.e. non-tradables, lower half), ii) are rather capital-intensive (left) versus rather labour-intensive (right), iii) involve rather cognitive activities (above) versus rather manual activities (below), each of which in turn can consist of iv) rather routine and often lower skilled tasks (centre) versus rather non-routine and often higher skilled tasks (corners). These criteria can help differentiate differences among platform markets, including the extent to which service provision in respective markets might be prone to automation.

This paper does not attempt to capture the whole range of services that can possibly be traded over platforms. Instead, it focuses on selected platform service markets, notably those for which new data could be gathered, in order to identify relevant characteristics of production in these markets, in particular the work and income opportunities they create and organisational aspects of such work. Financial services transacted via financial trading and crowd-funding platforms (including peer-lending and equity funding) are arguably less labour-intensive than services traded in other platform markets that are illustrated in Figure 2 and are therefore not discussed in this paper. 
Figure 2. Diversity of platform service markets

\section{Cognitive activities}

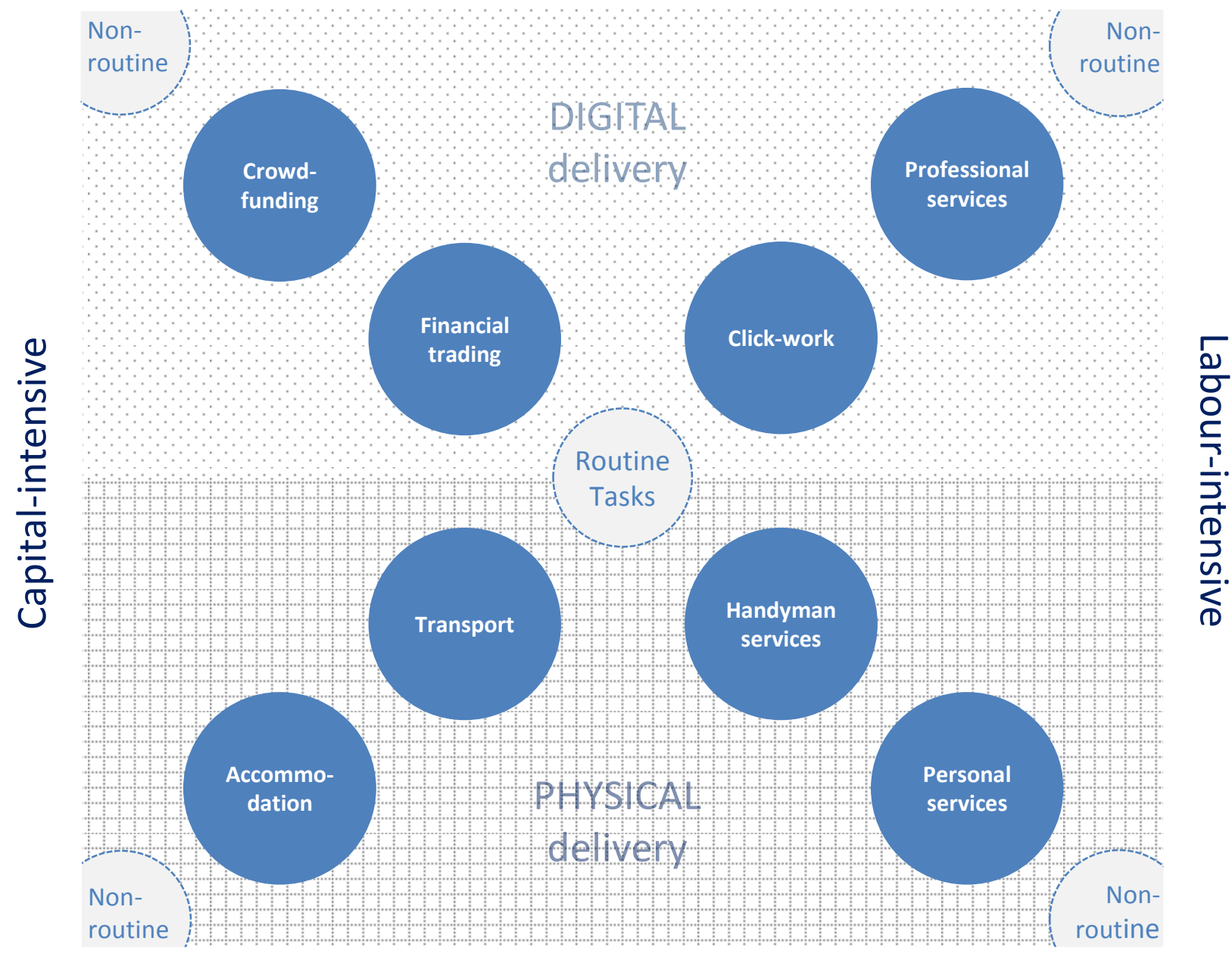

\section{Manual activities}

Source: OECD, 2016

\section{Services delivered physically}

Among the fastest growing online platforms in recent years are markets in which individuals sell accommodation and transportation. This can partly be explained by the fact that homes and cars are among the most expensive and underused assets owned by households and individuals. For example, the biggest expenditure items of German households in 2013 were homes (including energy and maintenance costs), which represented $34.5 \%$ of total household expenditures, and transport (including cars), which represented 14\% (DESTATIS, 2014). Despite being expensive, both of these assets are often underused. The average OECD four person household lives in almost seven rooms, with 2.5 rooms per person on average in Canada at the high end (OECD, 2015a). Cars typically stand idle for 23 hours per day, consuming valuable space instead of providing mobility (ITF, 2014). The possibility to monetise personal assets - fully or parts of their available capacity - over online platforms is being seized by a growing number of households and individuals as an opportunity to generate revenue from providing, for example, 
accommodation or mobility services. Such services are often cheaper than those from established providers, e.g. hotels or taxis, which fuels demand in and growth of platform markets. While numerous other privately owned durable goods are underused as well and could theoretically be monetised, their value and respective possible return tend to be too low in proportion to the remaining cost to transact in platform markets.

Among numerous platforms that operate markets for accommodation and other spaces, from holiday homes to storefronts, Airbnb has become a popular platform for short-term accommodation. Since its inception in 2008 in San Francisco, US, Airbnb extended its services into 34000 cities in 191 countries, counting over 1.5 million listings (Airbnb, 2015a). By October 2015, Airbnb hosts had accommodated a total of 60 million guests (bookings), half of which booked in 2014 (Airbnb, 2015b). Between 2010 and 2014, the compound annual growth rate of active hosts (i.e. hosts who hosted) and nights hosted in major Airbnb markets (United States, Germany, Spain, United Kingdom, and Italy) was 154\% and 189\% respectively. Over the same period, the annual number of rented nights per average Airbnb host also increased, from 41 to 67 nights (Figure 3). The annual number of nights hosted per median host was 37 (from 1 September 2014 through 31 August 2015 in major Airbnb markets); in other words half of all Airbnb hosts in these markets (134 200 hosts in 2014) rented their home or a room for more than one month per year, with variations across countries.

Figure 3. Airbnb hosts and nights hosted in the United States and major European markets

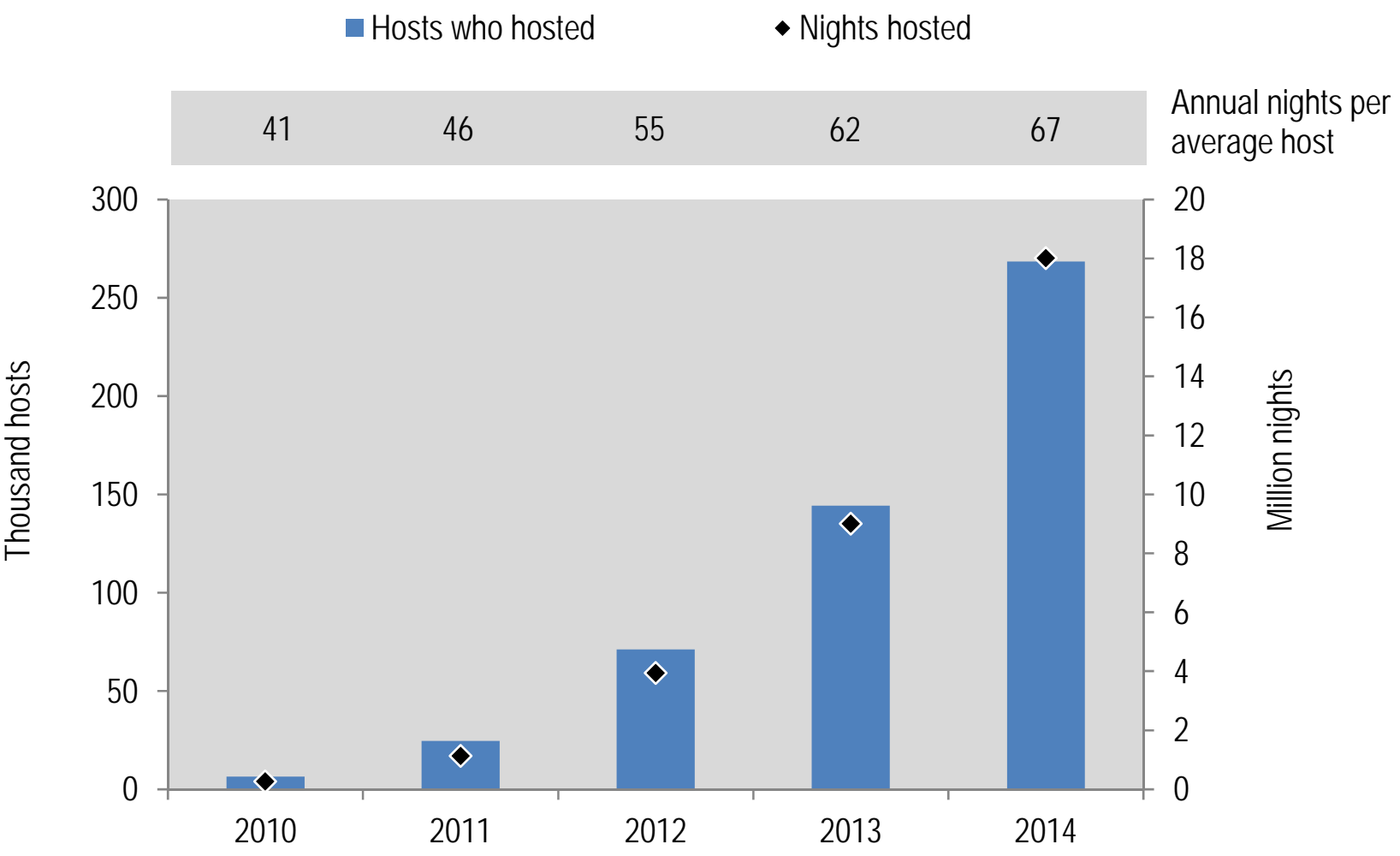

Note: European markets include: Germany, Spain, United Kingdom, and Italy.

Source: Airbnb, 2015c.

In some countries, a significant share of Airbnb hosts rent their entire apartment or house and many indicate that renting allows them to afford their home. Airbnb guests can book three different types of accommodation: the entire house or apartment of the host, a private room in the host's home, or a room 
shared with the host (e.g. a living room). The share of bookings in the latter category is negligible. In 2015, $68 \%$ of guests in major Airbnb markets booked entire homes and 31\% booked private rooms. Between 2010 and 2015, the share of entire home bookings evolved notably in Spain from 47\% to 72\%, in Italy from $65 \%$ to $76 \%$, and reversely in Germany from $81 \%$ to $65 \%$ (Figure 4 ). The increase in Italy and Spain might be related to the fact that both countries are more common holiday destinations than Germany; however, it might also indicate that, in the context of an enduring crisis, more Italian and Spanish hosts might use Airbnb to complement low or stagnating income as compared to German hosts.

Figure 4. Types of accommodation booked in major Airbnb markets

\section{- Entire home or apartment 2015}

$\% \quad \square$ Shared room 2015
- Private room 2015

- Entire home or apartment 2010

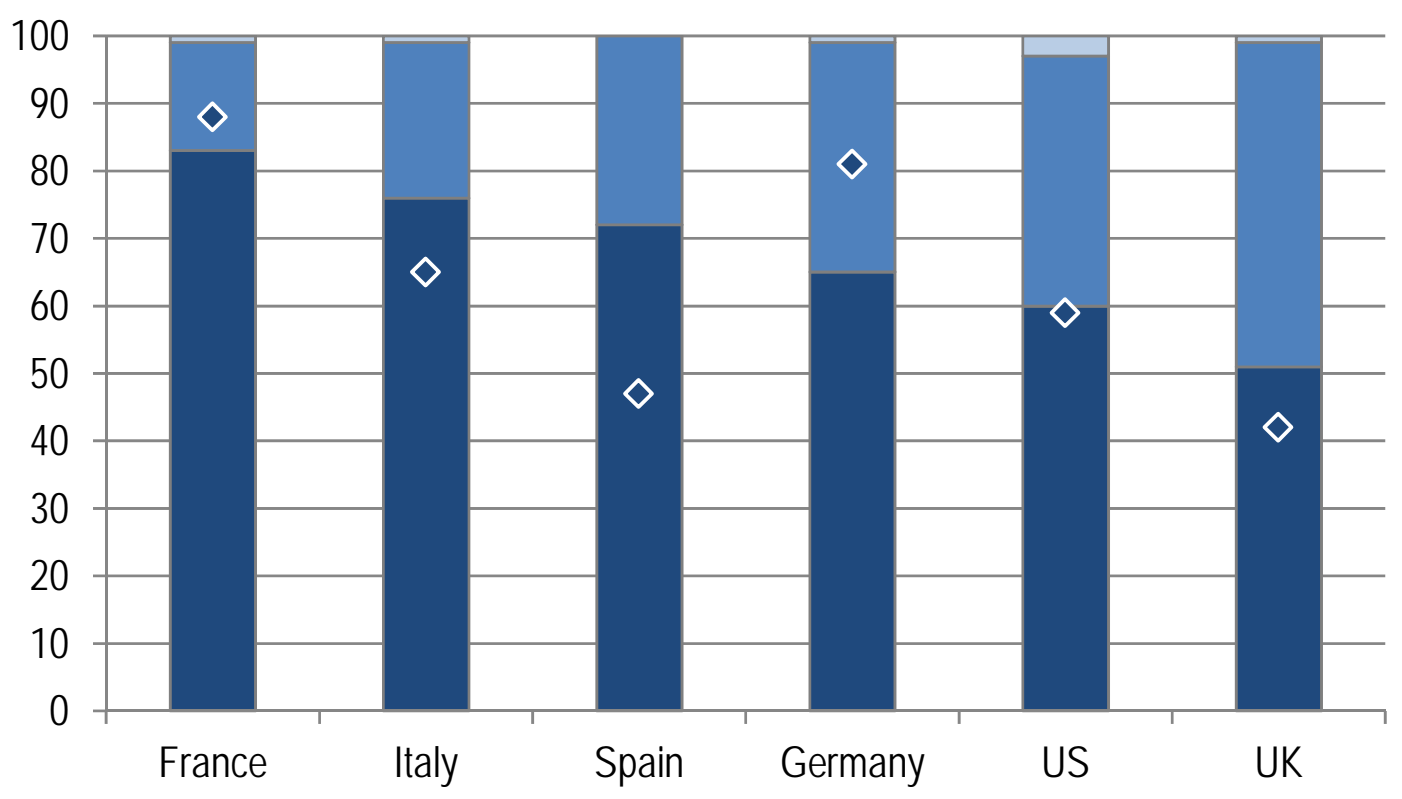

Source: Airbnb, 2015c.

Rental via Airbnb can be a significant source of supplemental income: annual revenues of typical hosts in major Airbnb markets are around the order of a monthly salary. The total income earned by hosts in the major Airbnb markets (between 1 September 2014 and 31 August 2015) amounts to over USD 1.6 trillion (Airbnb, 2015c, 2016a). A typical host in the major Airbnb markets makes USD 3383 per year, however, this figure varies significantly across countries. For example, typical hosts in the United States earn almost three times as much as typical hosts in Germany (Figure 5). Income tends to be higher in countries with higher average nightly prices per guest, notably in the United States and in the United Kingdom, where also the shares of short stays (1-2 nights) and of private room rentals are highest (Table 2 and Figure 2). The typical user of Airbnb in its major markets is in the mid-30s to mid-40s, with little variation across countries on the guest side, which are around 35, and slightly more variation in the average age of hosts in Spain (42), Italy (43) and Germany (39). These averages might hide a notable share of older hosts in some countries, for example in France, where 13\% of Airbnb hosts are retired (Airbnb, 2016a). Overall, $92 \%$ of hosts say that revenue from Airbnb supplements their regular household income. 
Figure 5. Average annual revenue from Airbnb and average nightly prices

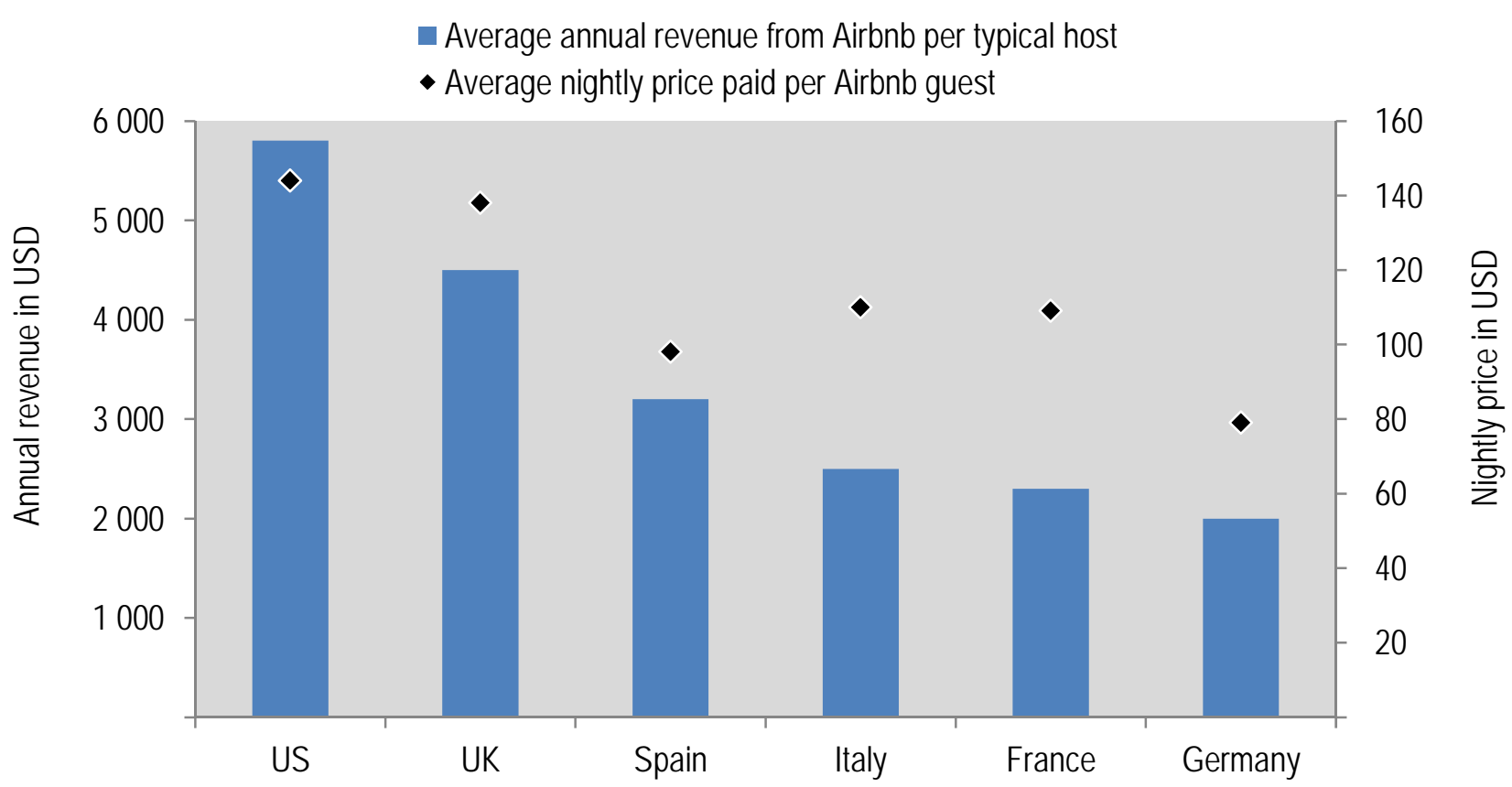

Note: A "typical host" is the median host who has at least a one-year history with Airbnb. Income values rounded to the nearest hundred. The data is based on trips done between 1 September 2014 and 31 August 2015.

Source: Airbnb, 2015c.

Many Airbnb nights seem to be booked for leisure, given that they are longer on average than typical stays in hotels. More than half of the bookings in the major Airbnb markets are for three nights or more, but for less than a month (Table 2). Only in the UK and in the US almost half of the bookings are for 1-2 nights, similar to the typical length of a business trip, which in the UK lasted 2.2 days on average in 2014-15 (Statista, 2015). Airbnb indicates that about 10\% of nights booked over its platform are for business purposes, and consequently has launched an Airbnb for business product, through which companies and employees get tailored accommodation and booking solutions for professional travel (Airbnb, 2015d).

Table 2. Duration of Airbnb stays in major Airbnb markets

\begin{tabular}{|c|c|c|c|c|c|c|}
\hline & $\begin{array}{l}\text { 1 or 2 } \\
\text { nights }\end{array}$ & $\begin{array}{l}\text { 3 or 4 } \\
\text { nights }\end{array}$ & $\begin{array}{l}\mathbf{5} \text { to 7 } \\
\text { nights }\end{array}$ & $\begin{array}{l}\text { > week } \\
\text { < month }\end{array}$ & > month & $\begin{array}{l}\text { 3 nights } \\
\text { < month }\end{array}$ \\
\hline Germany & $43 \%$ & $35 \%$ & $14 \%$ & $7 \%$ & $1 \%$ & $56 \%$ \\
\hline Spain & $33 \%$ & $35 \%$ & $22 \%$ & $10 \%$ & $1 \%$ & $67 \%$ \\
\hline France & $44 \%$ & $32 \%$ & $17 \%$ & $7 \%$ & $1 \%$ & $56 \%$ \\
\hline UK & $49 \%$ & $30 \%$ & $14 \%$ & $7 \%$ & $1 \%$ & $51 \%$ \\
\hline Italy & $44 \%$ & $35 \%$ & $16 \%$ & $5 \%$ & $0 \%$ & $56 \%$ \\
\hline US & $48 \%$ & $29 \%$ & $14 \%$ & $8 \%$ & $1 \%$ & $51 \%$ \\
\hline Average & $44 \%$ & $33 \%$ & $16 \%$ & $7 \%$ & $1 \%$ & $56 \%$ \\
\hline
\end{tabular}

Note: Based on data for stays in France, Germany, Italy, Spain, United Kingdom, and United States from 1 September 2014 through 31 Aug 2015.

Source: Airbnb, 2015c.

Another platform that scaled up quickly in many local markets over recent years is Uber. Uber matches customers and drivers for point-to-point transportation via a mobile application and offers a range of different products, from high-end chauffeur services to basic lifts. The former are often provided by professionals, the latter can be provided by non-professionals (peers) in some jurisdictions. In 2015, over 
1 million active drivers were working with Uber, many in the United States, where notably the number of drivers for Uber X, the most basic Uber service, has grown quickly (Plouffe, 2015; Hall and Krueger, 2015). Data on drivers working with Uber show different patterns for different countries. In the US and in Australia most drivers seem to work part-time, whereas in France and in the UK many work almost full time (Table 3). In the US, 69\% of drivers were found to drive in addition to another full- or part-time job, and Uber revenue was the only income source for $20 \%$ of drivers (Hall and Krueger, 2015). In contrast, only $21 \%$ of French drivers have a full- or part-time job in addition to working with Uber and respectively $79 \%$ can be assumed to have no other work-related income (Ifop, 2016). The gross average revenue figures reported in Table 3 need to cover the driver's expenses for delivering the ride, including gasoline, car depreciation, maintenance and insurance, as well as social security, health and pensions insurances, unpaid holidays, benefits, etc.

Table 3. Drivers, hours worked, and revenues in selected Uber markets

\begin{tabular}{|l|c|c|c|c|}
\hline & United States $^{1}$ & United Kingdom $^{2}$ & France & Australia $^{3}$ \\
\hline Active drivers & 160000 & 25000 & 14000 & $12680^{\star \star}$ \\
\hline Average driver age & 41 & no data & 34 & no data \\
\hline Average weekly hours driven & 20 & 27 & 27 & 19 \\
\hline Average annual revenue in USD & 16178 & no data & 25897 & 14097 \\
\hline Average hourly revenue in USD & 18 & no data & 22 & 17 \\
\hline
\end{tabular}

Note: ${ }^{1}$ US data accounts for UberX and Uber Black drivers; ${ }^{2}$ in the City of London; ${ }^{3}$ in the cities of Sydney, Melbourne, Perth and Brisbane; The revenue figures for France and Australia were originally expressed in EUR and AUD and are displayed in the table based on the respective 2015 annual average conversion rates ( 1.11 and 0.75$)$ to the USD.

Source: Hall and Krueger, 2015; Uber 2016a, Uber 2016b, Landier, 2016; Deloitte, 2016.

The trade of a larger range of personal and handyman services, beyond accommodation and transportation, is growing on platforms like TaskRabbit in the US or Youpijob in France. The services sold on such platforms commonly include gardening, cleaning, delivery, and other errand tasks. On Youpijob $37 \%$ of providers carry out do-it-yourself, moving or delivery jobs for an average value of USD 56 per job (Table 4). The majority are thus low paid mini jobs or tasks, of which Youpijob providers carry out 4 to 5 on average per year and gain average annual revenues of USD 475 (in 2015). On the demand side, the majority of clients use the platform on an ad-hoc basis, with two jobs posted per client on average since his or her registration. The average age of providers on Youpijob is 31 years, with $46 \%$ being between $18-25$ years old and 26\% being between 26 and 35 . This population seems particularly young compared to a larger population of providers in the French "collaborative economy", only 25\% of which are estimated to be aged 15-34 (GCD, 2015).

Table 4. Job categories and average job value by category on Youpijob, 2012-15

\begin{tabular}{|l|c|c|}
\hline Job categories & Share of providers & Average job value (USD) \\
\hline Do-it-yourself & $28 \%$ & 79 \\
\hline Moving and delivery & $19 \%$ & 71 \\
\hline Assistance & $12 \%$ & 49 \\
\hline Events & $12 \%$ & 32 \\
\hline Cleaning & $11 \%$ & 56 \\
\hline Gardening & $9 \%$ & 45 \\
\hline Information Technology & $9 \%$ & 74 \\
\hline Baby- and dog sitting & $7 \%$ & 39 \\
\hline
\end{tabular}

Source: Youpijob, 2015.

While platforms like Youpijob enable quick matching of labour demand and supply, it is less clear how effective they are in satisfying service demand in all places. The average time it takes from the moment a job is posted on Youpijob until a provider makes an offer is 5 hours, and after 21 hours, on average, the employer has selected a provider. Each posted job receives one offer on average, however, 
only 39\% of all jobs posted are actually being assigned to a provider. This figure is slightly higher (50\%) in the ten largest French cities. One explanation for the low percentage of job assignments could be that employers are posting jobs on different platforms simultaneously and might not always choose the offer from a Youpijob provider. Another explanation might be undersupply, notably in richer cities, where demand for Youpijobs seems to be higher than in poorer cities: Figure 6 shows that, proportionally, Youpijob attracts more providers (supply) in cities with lower GDP per capita, as opposed to more employers (demand) in cities with higher GDP per capita.

Figure 6. Demand and supply of Youpijob services in French cities

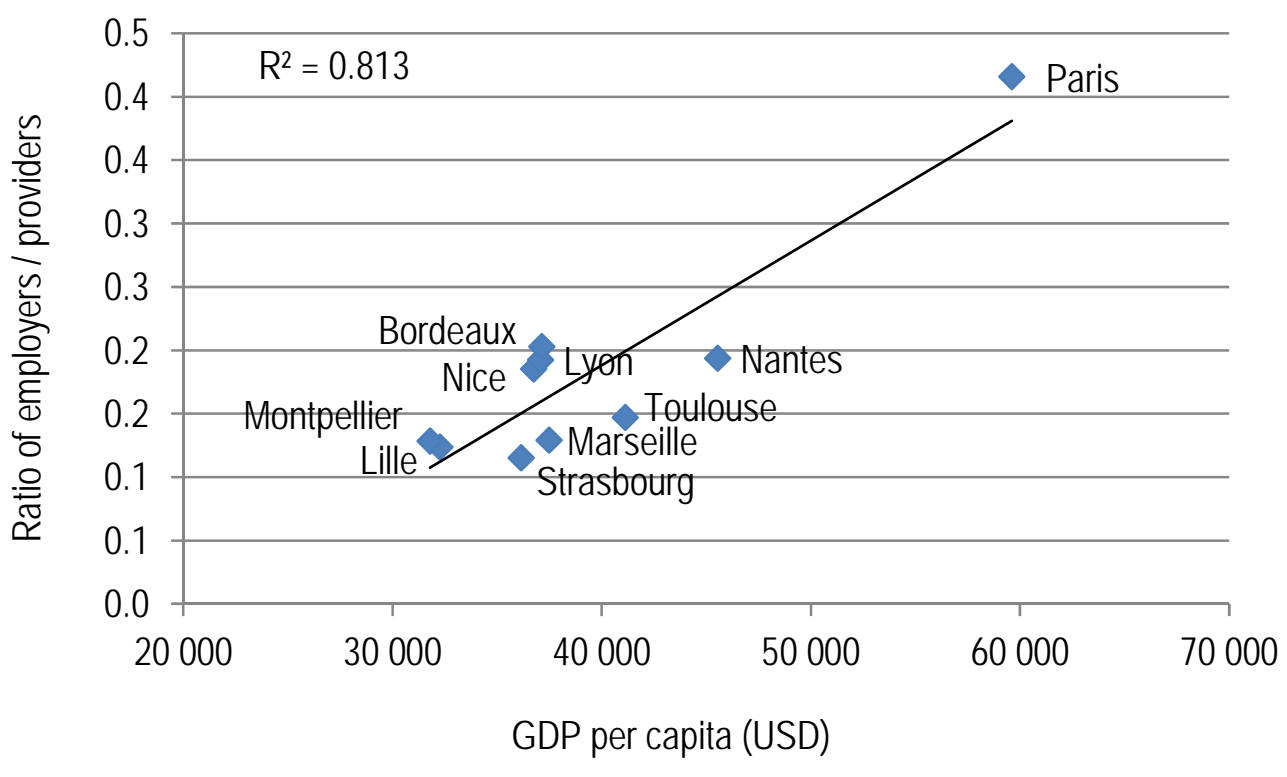

Note: Data on providers and employers is for 2015; GDP per capita values are for 2012.

Source: Youpijob 2015; OECD, 2015b.

\section{Services delivered digitally}

Services delivered digitally are increasingly provided over the Internet via platforms like Upwork and Freelancer, which mainly match professional service demand and supply. Clients - individuals or firms can buy a large range of services over such platforms, provided in many cases by professionals. While, in principle, participants in these markets can buy and sell from any geographical location, different prices, currencies, languages, time zones, and other factors, such as cultures, create barriers for the theoretically global reach of such platforms. The services transacted over these platforms range from data entry and administrative support, over translation or design, to coding, legal advice or business consulting. With over 35 million registered users combined, the currently two largest platforms are Upwork and Freelancer (Figure 7). By the end of 2014, Upwork had registered a total of 9.7 million freelancers and 3.8 million businesses, and reported USD 3.2 billion in service provider earnings (940 million in 2014, all categories combined) since the platform's inception in 2009 (Upwork, 2015a). Freelancer reached USD 3 billion of all time posted project and contest value in 2015 (Freelancer, 2016a). 
Figure 7. Registered users on selected platforms

Registered users on Upwork and Freelancer combined

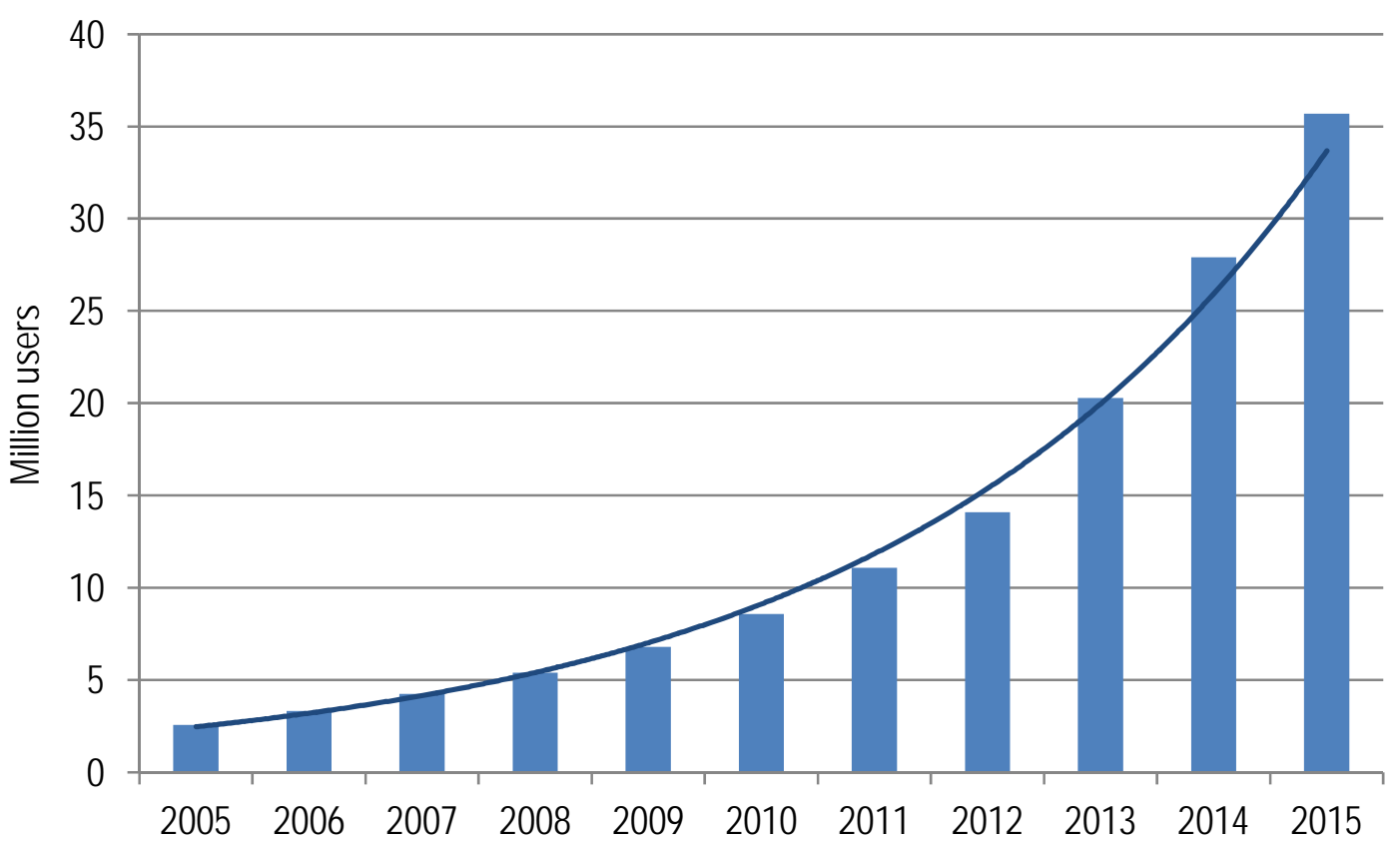

Note: Includes extrapolated figures based on most recent annual growth rates.

Source: OECD estimates based on data from Upwork (2015a) and Freelancer (2016).

Large number of job postings on Freelancer and Upwork seem to drive demand for low, medium and higher skilled services in many job categories. Upwork claims 3 million jobs posted annually and 1 billion worth of services provided per year (Upwork, 2016a). Freelancer registered 1.7 million jobs posted in 2015 (Freelancer, 2016a). The most important job categories on both Upwork and Freelancer, by transaction value, are technology, administrative support, writing, translation, design, architecture, and multimedia (Table 5). The fastest growing job categories on Upwork in 2014 were mobile, sales, marketing, and admin support, but also financial and legal services were growing fast (Table 6). Not much information is available on the value of service transactions in each category, however, in 2015, the overall average project value on Freelancer was USD 156 and the average project value for statistics services provided via Upwork was USD 145 (Freelancer, 2016b; Upwork, 2016b).

Table 5. Job categories on Freelancer and Upwork

\begin{tabular}{|c|c|c|c|c|c|c|c|}
\hline $\begin{array}{l}\text { Freelancer } \\
\text { top job categories }\end{array}$ & $\begin{array}{c}\text { Jobs } \\
\text { posted }\end{array}$ & $\underset{*}{\text { Share }}$ & $\begin{array}{c}\text { Growth } \\
2014 \\
\end{array}$ & $\begin{array}{l}\text { Upwork } \\
\text { top job categories }\end{array}$ & $\begin{array}{l}\text { Value in } \\
\text { USD mio }\end{array}$ & Share & $\begin{array}{c}\text { Growth } \\
2014\end{array}$ \\
\hline Websites, IT, Software & 62243 & $40 \%$ & $178 \%$ & Technology & 486 & $52 \%$ & $22 \%$ \\
\hline Design, Media, Architecture & 31435 & $20 \%$ & $136 \%$ & Admin support & 110 & $12 \%$ & $37 \%$ \\
\hline Writing, Content & 24564 & $16 \%$ & $155 \%$ & Writing, translation & 109 & $12 \%$ & $31 \%$ \\
\hline Data Entry, Admin & 12446 & $8 \%$ & $201 \%$ & Design, multimedia & 83 & $9 \%$ & $27 \%$ \\
\hline Sales, Marketing & 11960 & $8 \%$ & $219 \%$ & Mobile & 71 & $8 \%$ & $43 \%$ \\
\hline Translation, languages & 5977 & $4 \%$ & $183 \%$ & Sales, Marketing & 49 & $5 \%$ & $38 \%$ \\
\hline Accounting, HR, legal, other & 5122 & $3 \%$ & $151 \%$ & Finance, Legal & 33 & $4 \%$ & $30 \%$ \\
\hline
\end{tabular}

Note: Freelancer data is for 2015, based on the number of jobs posted per category per year; Upwork data is for 2014, based on spending by category.

Source: Upwork, 2015a, Freelancer, 2016a. 
Table 6. Fastest growing jobs and skills on Upwork based on earnings, 2014

\begin{tabular}{l|c|}
\hline Jobs most in demand & Growth \\
\hline Customer service agents & $92 \%$ \\
\hline User interface designers & $68 \%$ \\
\hline Front-end web developers & $54 \%$ \\
\hline iOS mobile developers & $45 \%$ \\
\hline Accountants & $43 \%$ \\
\hline Video Producers & $37 \%$ \\
\hline
\end{tabular}

\begin{tabular}{|l|c|}
\hline Skills most in demand & Growth \\
\hline QA testing & $147 \%$ \\
\hline Video editing & $133 \%$ \\
\hline Xero accounting software & $113 \%$ \\
\hline 3D design & $111 \%$ \\
\hline Zendesk customer services & $97 \%$ \\
\hline Source code management & $61 \%$ \\
\hline
\end{tabular}

Services provided digitally are prone to be traded across borders and much cross-border trade over platforms like Upwork and Freelancer is carried out between high- and low-income countries. Agrawal (2015) analyses relations between employer and provider countries, based on 2012 Upwork data, and finds strong cross-country hiring patterns, with over ten-times more employers in high-income as compared to low-income countries, and 4.5 times more providers in low- as compared to high-income countries. This pattern seems to be confirmed by more recent Upwork data (Table 7) as well as by the list of top employer countries (by completed projects in 2015) on Freelancer: US, Australia, United UK, India, Canada and Germany (Freelancer, 2016a). Employers in rich countries might offshore tasks either to save labour costs or to compensate local or domestic skill shortages. In either case, offshoring presents opportunities for providers in lower-income countries. It is worth noting, however, that on Upwork, the US and Canada also feature among the top 10 countries by freelancer earnings, which indicates the possibility of strong domestic hiring as well. Galperin (2015), who analysed data from Nubelo, a similar platform, also finds a propensity for domestic hiring in several Spanish speaking countries.

Table 7. Top 10 employer and provider countries on Upwork, 2014

\begin{tabular}{|c|c|}
\hline$<25 \%$ growth & 10-15\% growth \\
\hline Employer country & Provider country \\
\hline US & US \\
\hline UK & Philippines \\
\hline France & Russia \\
\hline Germany & Bangladesh \\
\hline Israel & UK \\
\hline Netherlands & Romania \\
\hline Singapore & India \\
\hline Switzerland & Ukraine \\
\hline Australia & Pakistan \\
\hline Canada & Canada \\
\hline
\end{tabular}

Note: Employer countries are listed based on employer spending; provider countries are listed based on freelancer earnings. Source: Upwork, 2015a.

\section{Patterns of work and income}

Working patterns in different platform service markets can differ significantly, but some common features can be identified: much work seems to be carried out in small units and irregularly. A good illustration is the accommodation market, which used to consist mainly of long-term private home rentals on the one hand, and short-term corporate rentals (hotels) on the other. With an average length of 4 nights per Airbnb stay in major Airbnb markets, the unit of output - the rental period - of private home rentals is much smaller than it used to be in home rental markets (Table 2). The annual average of 67 nights per average hosts in these markets furthermore indicates that accommodation is likely to be provided discontinuously. In point-to-point transportation markets, units of output (trip distance) are naturally small and Uber or similar platforms do not seem to change this; however, the fact that many drivers, at least in the US and in Australia, work part-time, is likely to imply irregular working patterns. In platform markets for handyman and personal services, units of output are clearly small (USD 56 average job value on 
Youpijob) and providers work irregularly (4-5 jobs per year). For platforms like Freelancer the average job value of digitally delivered services (USD 156 on Freelancer) indicates that services are provided in fairly small units as well. These observations resonate with findings from surveys about on-demand work in the US, which indicate that between $79 \%$ and $83 \%$ is carried out part-time (Intuit, 2015; MBO, 2014).

In most cases, platform-based revenue seems to complement other income, but a noticeable share of providers fully rely on it. Renting out rooms via Airbnb can yield significant returns, but the average figures presented above suggest that only few hosts, if any, earn the equivalent of a full-time salary with Airbnb. Data from Youpijob suggest that the revenues of providers in this market are mostly anecdotal. The available data on Upwork and Freelancer are insufficient to derive an assumption. As for drivers that work with Uber, many are part-timers in addition to having another job, in particular in the US. The same was found by a survey of US independent contractors (38\% of which were college students), $25 \%$ of which work in this status to top up income from a regular job, 25\% run a side business, $20 \%$ are contracting seasonally, e.g. in construction, and 8\% invest (Bloomberg, 2015). In France, a significant share of drivers works almost full-time with Uber and 79\% have no other job next to this activity (Ifop, 2016). In the UK, $24 \%$ of "crowd workers" are found to earn more than half of their income and $5 \%$ all of it in platform markets (RFS, 2015; University of Hertfordshire, 2016).

Patterns of work and income can be further differentiated based on a study of individuals' revenues from activities in a range of platform markets in the United States. A US Bank analysed data from 260000 individuals with revenues from activities in at least one of 30 distinct platforms out of a sample of 6 million clients that had an active checking account (at least five outflows per month) between October 2012 and September 2015 (JPM, 2016). This study distinguishes between labour platforms (e.g. Uber and Youpijob) and capital platforms (e.g. Airbnb and e-bay). Such a clear cut distinction is somewhat artificial, as illustrated by the continuous horizontal space between capital and labour in Figure 2 (e.g. an Uber ride is both capital and labour-intensive), however the study provides pertinent findings: notably that the average earnings from platform-based activities in a given month represent a significant share of the respective individual's total income in that month (Table 8), and that such earnings tend to either offset dips in non-platform income (notably earnings from labour intensive services) or otherwise supplement non-platform income (notably earnings from capital intensive services). The likelihood of labour platformbased earnings to substitute for non-platform income is furthermore supported by the finding that such earnings are higher when non-platform income is lower (JPM, 2016).

Table 8. Participation and revenue in platform markets in the US

\begin{tabular}{|l|c|c|}
\hline & Labour Platforms & Capital Platforms \\
\hline Share of months with earnings from platforms & $56 \%$ & $32 \%$ \\
\hline Average monthly earnings from platforms & & USD 314 \\
\hline Platform earnings as share of total income & USD 533 & $20 \%$ \\
\hline Traditionally employed individuals before platform career & $33 \%$ & $75 \%$ \\
\hline Traditionally employed individuals during platform career & $77 \%$ & $61 \%$ \\
\hline Platform market participants using multiple platforms & $66 \%$ & $1 \%$ \\
\hline
\end{tabular}

Note: ${ }^{1}$ Subsequent to a higher activity rate in the first 4 months of participation in the platform; ${ }^{2}$ in the months when individuals were actively participating in a platform; ${ }^{3}$ as of September 2015.

Source: JPM, 2016

The same study finds individuals that enter platform markets to be less likely employed traditionally, but also that reliance of such individuals on platforms does not increase over time. Table 8 shows that fewer individuals were employed in traditional jobs after having entered a platform market as compared to before. However, once individuals are active on a platform, they do not seem to increase their reliance on platform-based revenues: both the frequency of such revenues and their share in individuals' total income are found to stay stable over time (the 36 months observed in the study). 


\section{WORK IN PLATFORM SERVICE MARKETS}

\section{Opportunities}

Work in platform service markets (PW) can often be carried out flexibly, which creates opportunities for those who would otherwise not work or those who can choose the time and place of work. Surveys carried out by platforms with their participants confirm that flexibility, both temporal and spatial, is important for many providers (Nubelo, 2014; Hall and Krueger, 2015; Ifop, 2016). Individuals who might not be able to, or not be interested in working full or at fixed times include, for example, caring mothers and fathers, students or pensioners. Individuals that might benefit from providing services remotely over the Internet include women that are not allowed to work in their country, physically handicapped, or talented individuals that find no demand for their skills in local markets. Platform markets for lower skilled services, such as driving, tend to have low entry barriers, including for unemployed, as was demonstrated by a study of Uber drivers in France (Landier et al., 2016). Providers with high skills that sell their services over platforms like Upwork could probably find work elsewhere, but might choose platform-based work for its flexibility or for financial reasons, if demand for their services and pay is higher online as in other markets.

From the perspective of firms and other producers, platforms create fluid input markets that can be particularly beneficial for small and medium enterprises (SMEs), but also for large organisations. Smaller firms often lack the capacity to hire permanently and full-time, notably if the input is required for a noncore business activity. Digital services available online in small units can be flexible inputs for such (and other) firms and online platforms might offer more diverse and less expensive inputs than those available in local markets. A firm survey (54\% of which are small firms with 2-10 employees) on the platform Nubelo finds that the main reasons for firms to hire is the simplicity of finding talent (58\%) and the possibility to save money compared to traditional hiring (52\%) (Nubelo, 2014). Agrawala et al. (2015) find that the main advantages for buyers on oDesk (now Upwork) to source labour and talent online are: "remote is less expensive" (76\%), "can get work done faster remotely" (46\%), "difficult to find local talent" (31\%), and "no room/equipment" (21\%). Beyond the advantages for SMEs, online sourcing can be attractive for large organisations as well: for example, NASA has repeatedly used Freelancer for the design of high-tech components used in space explorations.

Income from PW can be greater or smaller, depending on the service in question and the means of provision. As illustrated in Figure 2, services tend to be either rather capital- or rather labour-intensive and might require either rather manual- or rather cognitive skills to be produced. The more labour-intensive a service, the more time is needed to provide it, e.g. cleaning or dog-sitting, less time in turn is needed to provide capital-intensive services such as credit or accommodation. Services that require mainly cognitive skills are likely to pay better than services provided mainly manually, and it could thus be assumed that most platform-based non-tradable manual services (delivered physically) are likely to pay less than tradable digital services (delivered digitally). However, the limited available data does not yet allow testing this assumption; and one could assume to the contrary that the (potentially global) competition on platforms for tradable digital services might drive prices down to the highest quality offer from the country with the lowest income level. As for non-tradable services provided manually, data on a Belgian platform shows that hourly revenue of providers on that platform tend to be above the domestic minimum wage and above average hourly wages in corresponding traditional markets, except for babysitting (De Groen et al., 2016). 


\section{Challenges}

The flexibility of PW can turn into a challenge if service providers are not in power of their time or are forced into working more or in worse conditions than in traditional markets. For example, if individuals have to respond to employers' requests on-demand, flexibility can easily turn into stress and unpaid waiting time for the provider. In some cases, providers are rated for their responsiveness, even when not working, which can create additional stress. When clients buy services produced in other time zones, they might force providers to work at inept times, including night shifts. Advantages of flexibility are also compromised if providers cannot find jobs or task when needed or desired. This can happen for different reasons, for example, demand in local markets might not be sufficient at any given time, and in global markets providers located in high-income countries might not be able to compete with those in lowerincome countries.

Flexibility can also become a challenge when it leads to multi-jobbing that not everyone might be equipped to handle well. Given the ad hoc and task-based nature of much PW, some providers are prone to pursue several activities in parallel to make a living. Hardly any data on multi-jobbing, notably in the context of PW, is available so far, but a recent study of participants in "labour platforms" in the US finds that $14 \%$ engage on multiple platforms (Table 8 ). Combining different jobs and fulfilling a discontinuous stream of tasks for changing clients might notably pose challenges in terms of: i) handling work time and focus, ii) calculating the profitability of an activity, taking into account all costs, iii) building expertise and a profile that can attract traditional employers, iv) ensuring continuous training, and v) building professional networks, to name just a few. While these challenges apply in principle to all freelancers, they are becoming more pertinent in the context of PW.

The theoretical availability of an infinite pool of digital service providers online, the "crowd", facilitates the segmentation of jobs into smaller tasks and potentially the commodification of work. Building on the assumption that specialisation benefits most firms, which in turn tend to cut production processes and inputs into smaller units that can be provided separately and easily be assembled, digital service providers can cater the resulting demand for small inputs. While firms might benefit, providers might become dependent on highly specialised activities and might not find such digital "assembly line" work satisfactory. Routine and low-skilled tasks can be expected to be most prone to be cut into small discrete tasks that can be commoditised. So called "click-work", for example, carried out over platforms like Amazon's Mechanical Turk, already consists mainly of micro-tasks, which can be as simple as having one's eyeballs tracked while watching a movie in front of a camera (Romei, 2015). But also higher skilled tasks, such as routine activities in legal or financial services, might well be subject to more segmentation and standardisation.

The smaller and the more standardised the in- and outputs, the easier it becomes to automate production. Whether and which jobs, occupations and tasks can be automated, is a debate that goes beyond the scope of this paper. However, a recent study estimates that in OECD countries, on average 9\% of jobs are at high risk of being automated (Arntz et al., 2016). Some online platforms specialise on the moving frontier at which machines still fail to carry out tasks by employing humans to help machines to learn. For example, Mechanical Turk administers around 350000 "human intelligence tasks" (HITs) at any point in time, which are sold to a crowd of "turkers" who provide "artificial artificial intelligence", as Amazon puts it. While such human enhanced machine learning helps pushing the automation frontier towards more complexity, platforms or software like WorkFusion help cut complexity of production processes down into smaller and more standardised activities that could eventually be carried out by machines. 


\section{NON-STANDARD WORK IN OECD COUNTRIES}

\section{Trends in non-standard work}

Much of the work in platform service markets (PW) discussed above is likely to be some form of non-standard work (NSW) (Box 2). Sections 2 and 3 show that the hours worked and revenues earned in platform service markets are still small in total, but also that PW is likely to become more significant, if these platforms keep growing at the current pace. Much PW has furthermore been found to be carried out irregularly and revenues from such work tend to supplement other income sources. Irregular work can be performed as i) temporary or ii) part-time work, and is in many cases iii) self-employment. These three categories are measured by the OECD as NSW. While PW can also take forms that are not captured by the information on NSW presented below, this data and analysis provide relevant insights for those forms of PW that are similar to or overlap with NSW. The need to better measure new forms of work, in order to improve such analysis, is discussed in Section 5.

\section{Box 2. Defining non-standard forms of work}

In its broadest sense, NSW arrangements are defined by what they are not: full-time dependent employment with a contract of indefinite duration, or what is generally considered the "standard" work arrangement. This definition generally implies that self-employed own-account workers and all part-time workers fall under "non-standard workers". While problematic - as this lumps together precarious and non-precarious forms of work - this convention is followed by a large part of academic international and national research (e.g. Houseman and Osawa, 2003; Wenger, 2003; Görg et al., 1998; Kalleberg et al., 1997; Kalleberg, 2000; Leschke, 2011), as well as by international organisations (e.g. International Labour Organisation, World Bank, Eurofound).

This section breaks down non-standard work into three separate categories: 1) self-employed (own-account), 2) temporary full-time employees and 3) part-time employees (including permanent and temporary contracts). Unpaid family workers are excluded from the analysis. The distinction between different forms of employment has become increasingly blurred. There is a growing grey area, for instance between self-employment and wage employment (OECD, 2000). The growth in the numbers of self-employed contractors working for just one company or franchisees constitute groups on the borders of dependent and self-employment. Temporary jobs for the purpose of this analysis are defined as dependent employment of limited duration, including temporary work agency, casual, seasonal or oncall work. Part-time employees are defined based on their weekly working hours, namely working less than 30 hours per week. This may differ from national definitions which use different hours thresholds. Part-time work is further disaggregated into part-time temporary and part-time permanent jobs when data is available.

Definitions across countries outside the European Union are not harmonised and are based on different approaches. For Korea, workers in temporary jobs include fixed-term jobs or jobs of a limited duration, which is close to so-called contingent workers, as well as other atypical workers, i.e. temporary agency workers, individual contract workers, at-home workers, on-call workers and others. In the case of Australia, a broad definition of temporary work includes jobs of fixed-term duration, those employed through a labour hire or a temporary work agency as well as casual workers. Casual workers may lack entitlements to key fringe benefits such as paid vacation or sick leave or may not be protected by legislation against unfair dismissal, but might otherwise have continuous and stable employment, and are therefore one form of atypical or NSW. In this respect, this definition follows the work of the Australia Productivity Commission (2006) in classifying casual work as one form (the most sizeable one) of non-standard work.

Figures on non-standard work are not easily comparable across countries because of national differences in definition and measurement. The difficulties in defining non-standard work on a comparable basis are accentuated if attempts are made to link non-standard forms of work with wages and household earnings, as few data sources contain information on both employment and wages over time. Self-reporting errors may be present in such information, and figures should be used to indicate broad levels and trends across countries.

Source: based on OECD, 2015c. 
The share of NSW in many OECD countries' workforce is significant and growing. Across (29) OECD countries the average of the NSW share in total employment is $33 \%$ and contains almost equal portions of temporary jobs, part-time work and self-employment (Figure 8). Without counting permanent part-time work, the category that seems least likely to occur as PW, the average share of NSW is $22 \%$ in these countries. The average share of self-employment, the category that seems most likely to occur as PW, is $10.5 \%$; self-employment is particularly common in Greece, the Czech Republic, Slovenia and Turkey. Between 2007-2013, the share of NSW has grown by $0.8 \%$ in (26) OECD countries on average, while over the same period, on average $2.8 \%$ of standard work (permanent full-time employment) was destroyed (Figure 9).

Figure 8. Non-standard work as a share of total employment, 2013

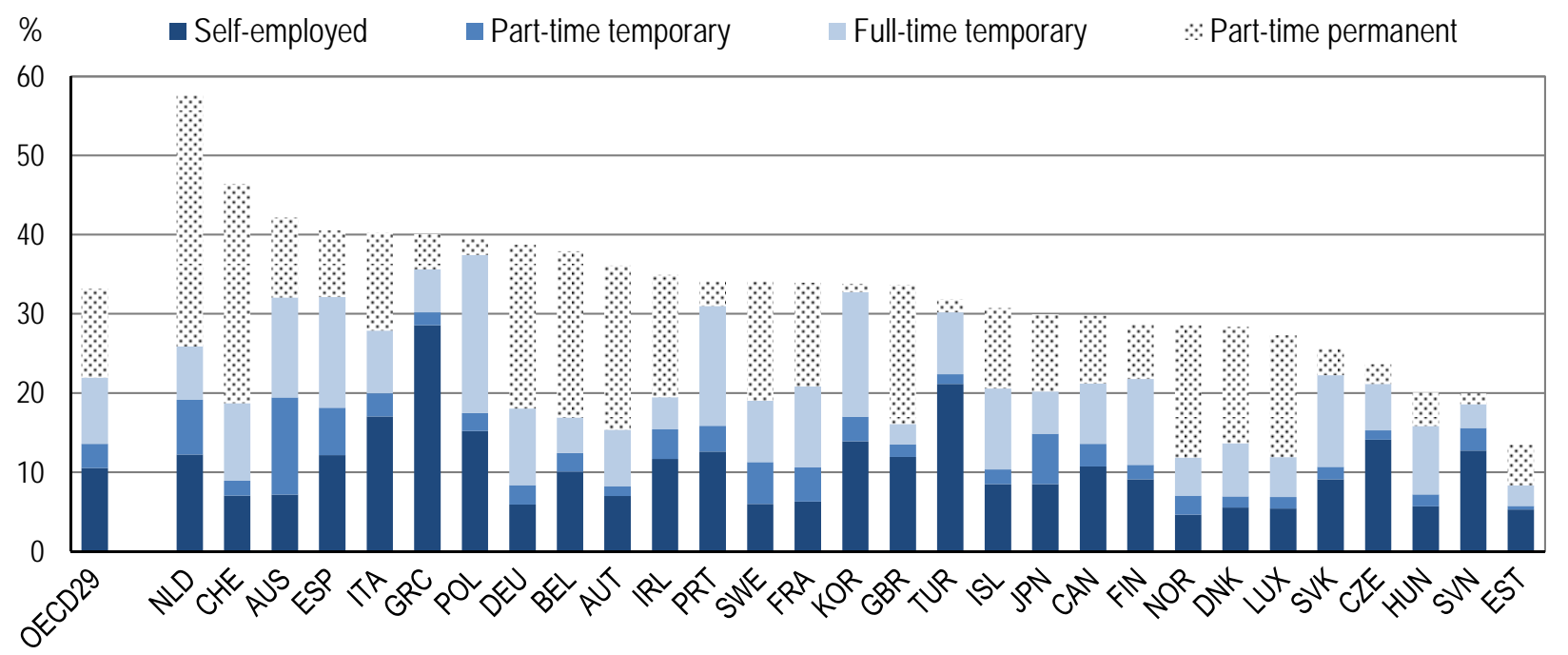

Note: Sample restricted to paid and self-employed (own account) workers aged 15-64, excluding employers, student workers and apprentices. For Australia, $42.6 \%$ of full-time temporary contract are casual; and $85.2 \%$ of part-time temporary employees are casual.

Source: OECD, 2015c.

Figure 9. Employment growth by type, 2007-2013

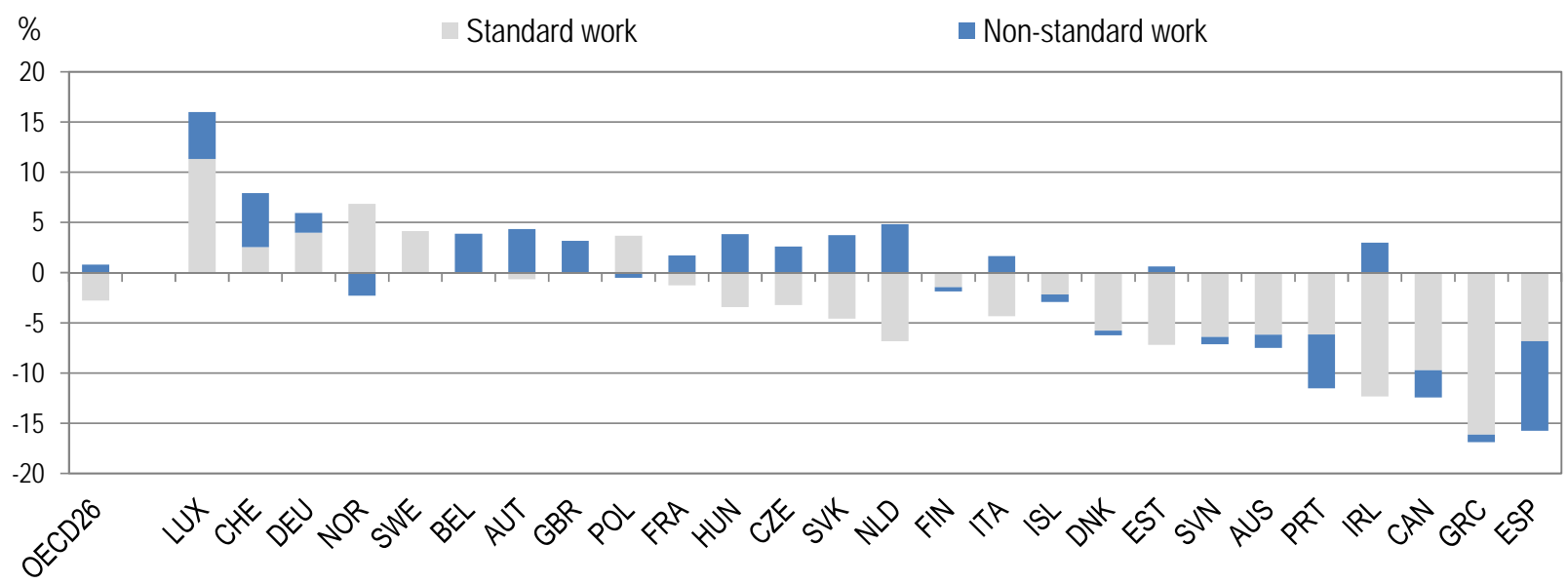

Note: Working-age (15-64) workers, excluding employers and students working part-time. Countries are ranked from left to right in decreasing order for total employment growth. Temporary for Australia includes both casual and fixed-term work.

Source: OECD, 2015c. 
NSW trends in the US are more difficult to assess, given the unavailability of comparable statistics. Official statistics show a mixed picture: on the one hand, US Bureau of Labor Statistics data show that the number of self-employed workers has decreased between 2008-2011 and has stagnated with fluctuations between 2011-2015; on the other hand, US Census data shows that the number of non-employer establishments has significantly increased from 2008-2013 (Figure 10). Non-employer establishments are business owners who are subject to federal income tax and have no paid employees, most of which, by Census' description, are "self-employed individuals operating very small unincorporated businesses" (Donovan et al., 2016). In combination, the growing number of non-employer establishments between 2008 and 2013 compensates for the decrease in self-employed over the same period and leads to about 1 million more self-employed (non-employer establishments) in 2013 than in 2008. Some suggest that this increase might partly reflect the emergence of PW over that period (Donavan et al., 2016).

Figure 10. Self-employed workers and non-employer establishments in the United States

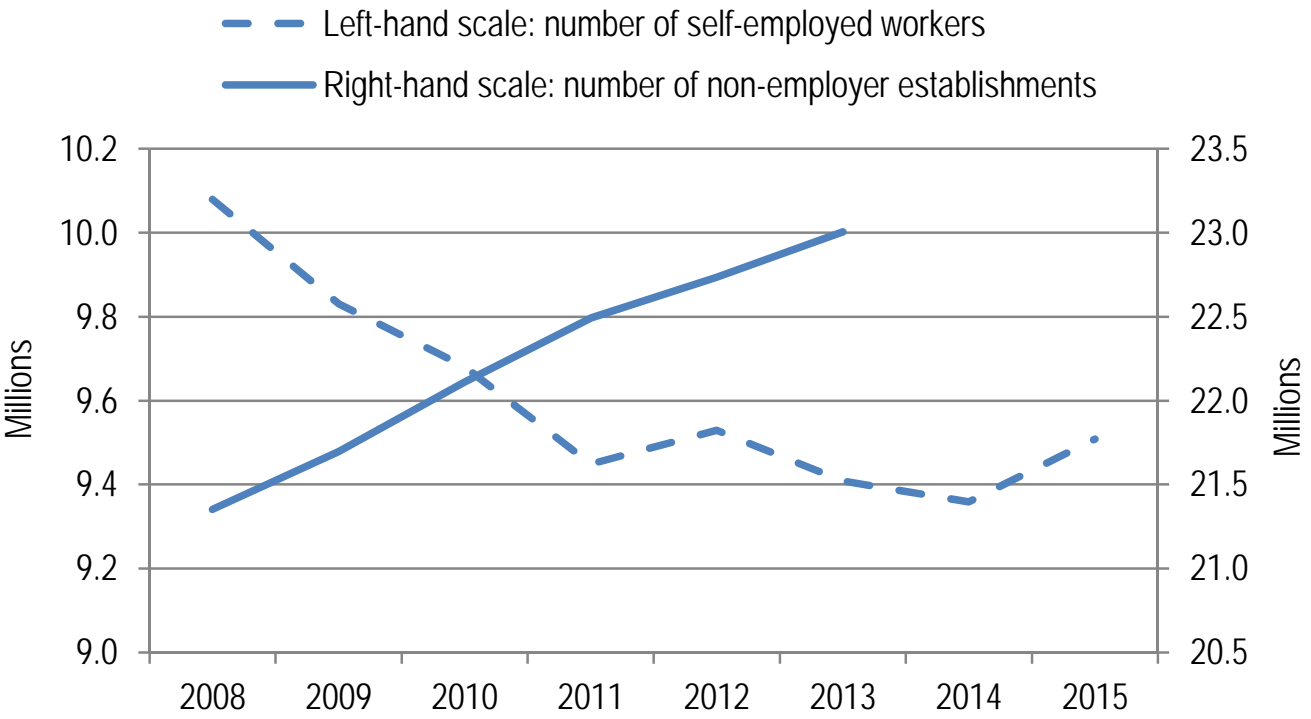

Note: A non-employer establishment is a business "that has no paid employees, has annual business receipts of USD 1000 or more (USD 1 or more in the construction industries), and is subject to federal income taxes."

Source: BLS, 2015b; USCB, 2015.

Much PW is likely to be temporary and OECD data shows that temporary jobs are often not entered into voluntarily. An analysis of the labour market for Uber's driver-partners in the United States shows that $60 \%$ of drivers were actively looking for a job prior to working with Uber. Half of the drivers were looking for a part-time job, the other half were looking for a full time job; in France, 25\% of drivers were found to be unemployed before working with Uber (Hall and Krueger, 2015; Ifop, 2016). Uber data furthermore shows that in the US, after 6 months of working with Uber, 30\% had stopped and that after one year just over $50 \%$ of drivers were still working with Uber (Hall and Krueger, 2015). A survey of independent contractors in the US found that less than $30 \%$ intended to continue their job for three years or more, the rest considered their activity of short duration (48.5\%) or did not know how to continue (27.7\%) (Bloomberg, 2015). Another survey finds that $43 \%$ of independent contractors quote insufficient pay as the main reason to end their work, $37 \%$ mention a lack of enjoyment from work, and $28 \%$ say they stopped working because the job was no longer needed (RFS, 2015). OECD data shows that more generally, contracts of limited duration are often not the first choice, but rather entered into because individuals could not find a permanent job (Figure 11). 
Figure 11. Reason for having a contract of limited duration

Percentage of employees with a fixed-term contract, 2011-12

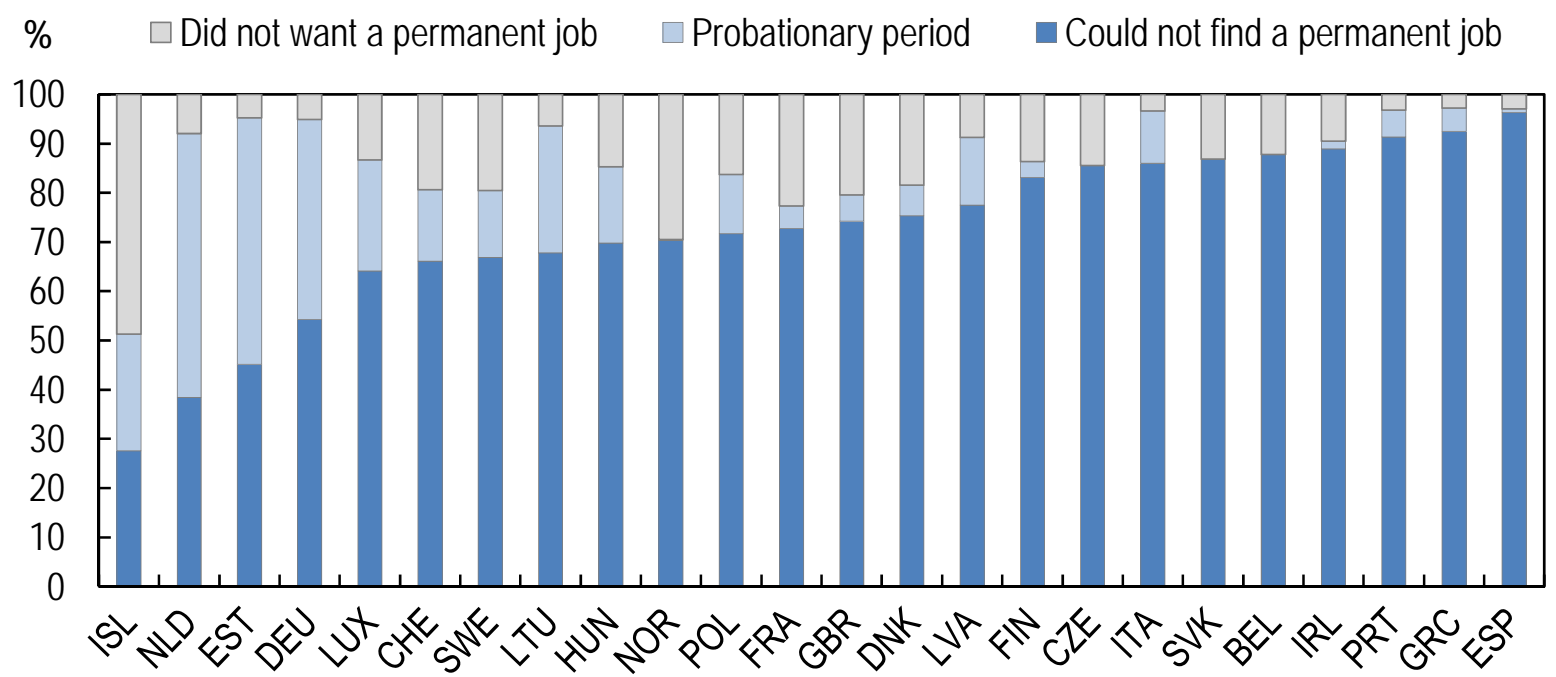

Note: Students or apprentices in regular education are excluded.

Source: OECD, 2015c.

\section{Effects of non-standard work}

OECD analysis of NSW in a range of OECD countries has found that non-regular employees are likely to earn less than full-time permanent employees, or at least unlikely to enjoy a wage premium. Figure 12 presents estimated average differences in hourly wages between non-regular and full-time permanent (standard) employees, expressed in percentages of the standard employee wages. These estimates do not include differences in benefits between non-regular and permanent employees, which, in most countries, are linked to permanent jobs. Furthermore, pay gaps are likely to increase over time, given that wage growth for temporary workers is lower on average than for standard employees (OECD, 2015c). In principle, these findings can be expected to apply also to temporary PW. However, it is worth noting that data for some platforms show gross hourly income of workers in several sectors to be higher than minimum wage, and possibly higher than for workers in corresponding traditional markets (De Groen et al., 2016; Uber, 2015). The shortcoming of such data is that it does not account for the investment and running that providers must cover with their gross revenue on platforms.

Temporary workers are also less likely to receive employer-sponsored training (Figure 13). While firms usually have an interest in training their permanent staff, the shorter the time a worker is employed for, the lower the incentive for the employer to provide training. Many clients that hire on platforms like TaskRabbit or Upwork are likely to have no incentive to train their providers, except in cases of repeated or long-term hiring. Platform operators might eventually see the benefit of training providers, in order to increase the quality and value - and respectively the operator's revenue - of services transacted in their market. For example, Airbnb provides hosts with a free photographer in many places, to professionally document apartments to be offered on the platform, and offers advice to improve hosts' services. Uber instructs drivers to streamline and to improve quality of service. However, these examples cannot yet count as systematic training offered by or on platforms. 
Figure 12. Wage penalty for non-regular employees

Estimated wage difference between full-time non-regular and permanent employees

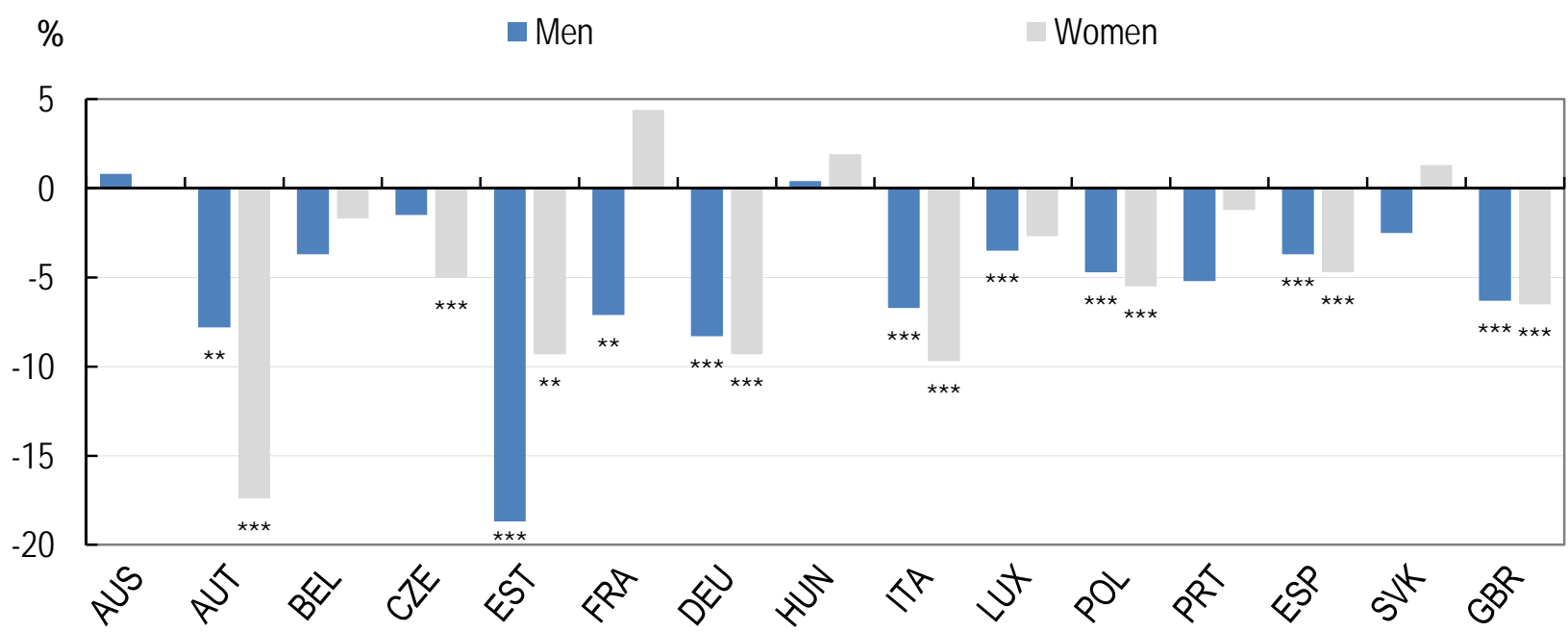

Note: Estimates are obtained through a fixed-effect linear model of log hourly wages controlling also for dummies for five age classes, three education levels, married status, children below 13 years and bad health conditions as well as region and time dummies. Casual workers are classified as non-regular employees. ${ }^{* \star},{ }^{* *}$ : significant at the $1 \%$ and $5 \%$ levels, respectively.

Source: OECD, 2014.

Figure 13. Temporary workers and employer-sponsored training

Estimated \% effect of temporary contract status on the probability of receiving employer-sponsored training, 2012

$\%$

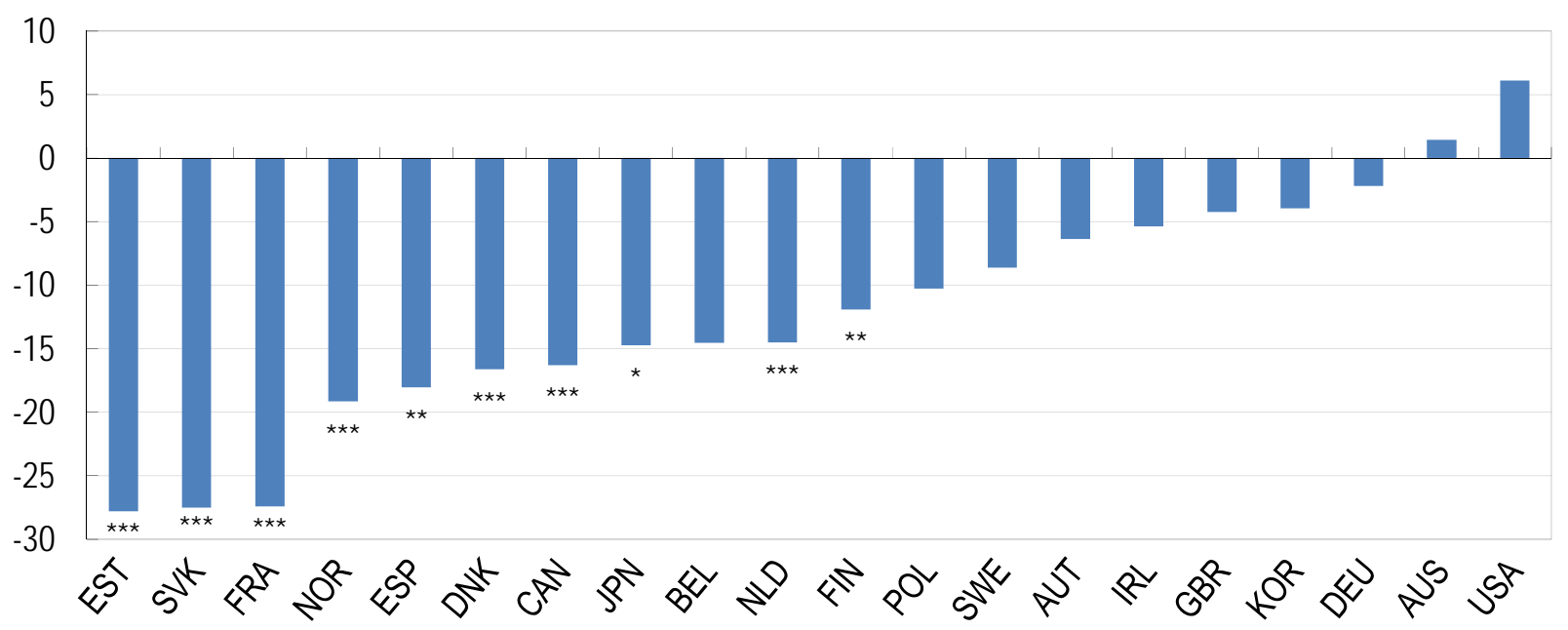

Note: Estimated percentage difference between temporary and permanent workers in the probability of having received training paid for or organised by the employer in the year preceding the survey, obtained by controlling for literacy and numeracy scores and dummies for gender, being native, nine age classes, nine occupations, nine job tenure classes and five firm size classes. Data are based only on Flanders in the case of Belgium and England and Northern Ireland in the case of the United Kingdom.

***, **, *: significant at the $1 \%, 5 \%, 10 \%$ level, respectively - based on robust standard errors.

Source: OECD, 2014. 
Some suggest that NSW is a stepping stone into standard work; however, OECD data rather suggests that NSW tends to be a trap. One indicator used by the OECD as a proxy to estimate the likelihood of moving from part-time to full-time employment is the "transition tax rate" (TTR), which measures how much of the earnings increase is "taken away" in the form of higher taxes and lower benefits when moving from 20 to 40 hours of work per week. In 2010, the average TTR in (29) OECD countries was 48\%, ranging from below one-third of earnings being "lost" when worked more in Korea, Spain and Portugal to two-thirds in Denmark, the United Kingdom, Ireland, Japan and the Netherlands. TTR for self-employed moving from part-time to full-time work tend to be similarly discouraging (OECD, 2015c). Non-regular workers are furthermore found to have a significantly higher probability of being in unemployment one year after their current NSW arrangement as compared to full-time regular workers in many OECD countries (Figure 14). The same is true for non-regular workers' likelihood to transition into inactivity (OECD, 2014).

Figure 14. Probability for transitioning from employment to unemployment in one year

Percentage-point difference between non-regular workers and full-time permanent employees

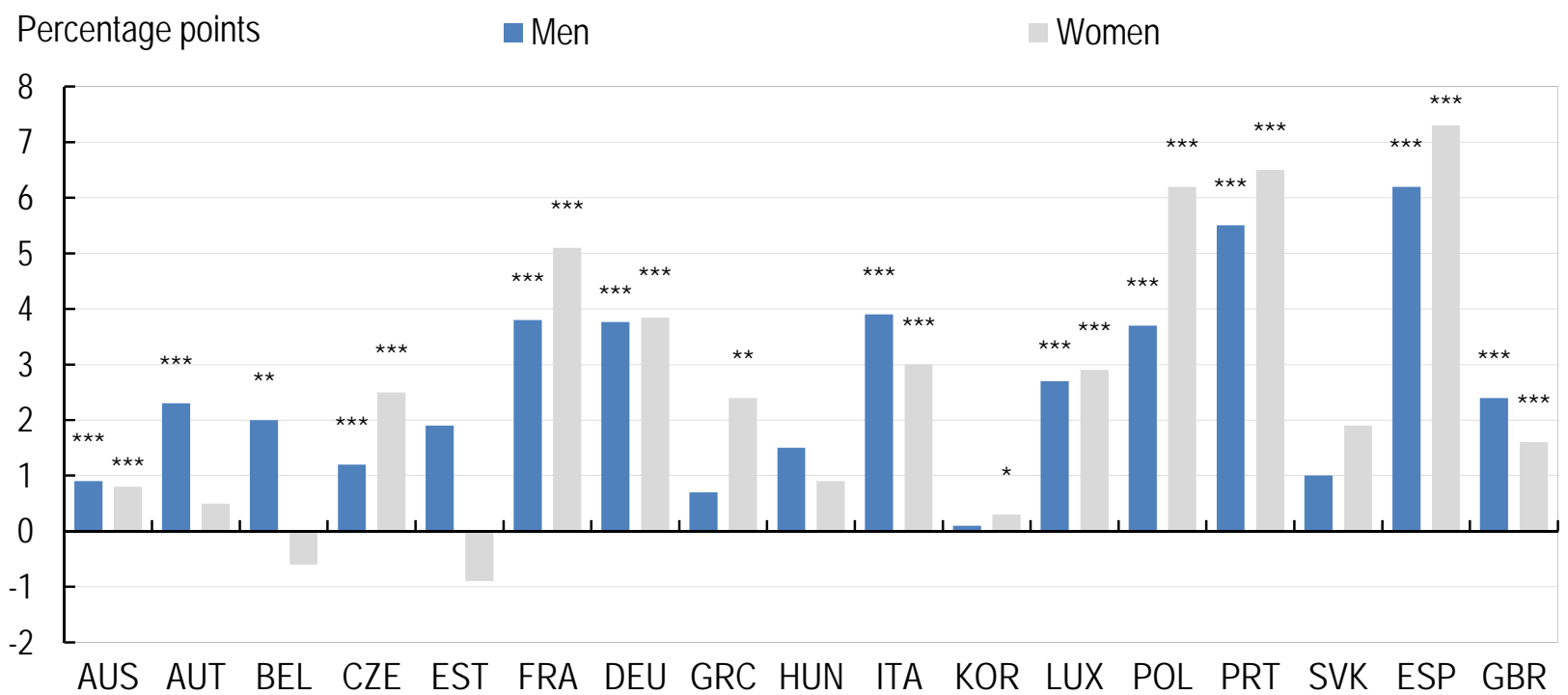

Note: Estimates are obtained through a random-effect probit model controlling for six initial employment statuses (full-time permanent, part-time permanent, non-regular employees, unemployed, inactive and self-employed), household income, and dummies for three age classes, three education levels, married status, children below 13 years and bad health conditions as well as region and time dummies. Casual workers are classified as non-regular employees. ***, **, *: significant at the 1\%, 5\%, 10\% level, respectively based on robust standard errors.

Source: OECD, 2014.

In addition to greater job insecurity, potentially lower earnings and less employer-sponsored training, self-employed workers are likely to receive less work-related benefits than standard employees. This is the case notably for unemployment benefits, eligibility for work injury benefits, as well as for sickness and maternity benefits (OECD, 2015c). In the United States, contingent workers are two thirds less likely than standard workers to have a work-provided retirement plan and are also less likely to have private or workprovided health insurance (GAO, 2015). Correspondingly, the RFS (2015) survey finds that health insurance, retirement benefits, and paid sick and vacation days are the three most desired benefits among the "1099 workforce" (independent contractors) in the US. 


\section{POLICY DISCUSSION}

\section{An evolving policy discussion}

With the rise of platform service markets, a number of policy and regulatory issues have emerged. At least two types of issues can be distinguished: i) sector specific issues, for example, those related to transportation or accommodation, and ii) cross-cutting issues, related, for example, to work and labour markets, consumer protection, taxation, competition, and privacy. Much of the recent policy discussion and regulatory efforts regarding platform markets have focussed on sector specific issues, while several of the cross-cutting issues have received less attention so far and are not yet analysed in great depth. This paper attempts to contribute to a more informed discussion of issues directly or indirectly related to work in platform service markets.

A core element of the analysis in this section is the individual provider, who, in platform service markets often works independently and in new ways. As demonstrated in sections 1 and 2, platforms lower barriers for individuals, including for non-professionals, to enter service markets that often have been confined to firms and professionals before. Providers who always worked independently might use platforms to market and sell their services online and stay competitive. Whatever the starting point of independent providers, if platform service markets continue growing, so will the number of workers and earners in these markets.

A core aspect of individual providers' work is flexibility, which in the first place is an opportunity, but can turn into a challenge and can have trade-offs, as discussed in sections 3 and 4 . The more fluid platform markets are, the easier it becomes for providers to opt in and out of work when needed or desired, and to combine different jobs and income sources. An Uber driver, for example, simply opens her app when she decides to work and closes it when she wants to stop. The same is true for an Airbnb host, who decides when to rent a room or the entire home. How free such decisions are, however, depends on the economic pressure that may drive some individuals to carry out easy entry PW. Individuals who are not equipped to manage the risk of independent work, and possibly of multi-jobbing, may accept economic and social trade-offs, rather than exploit the potential opportunities of PW.

\section{Selected policy issues}

\section{Provider status}

Some individual providers in platform markets only work occasionally, earn limited income, and in many cases have no worker status. For example, an individual who rents a room via Airbnb, does some click-work, or drives an Uber pop (in the United States) once in a while probably does so in order to complement other income, rather than to exercise this work as a main profession and sole source of income. While such ad hoc and irregular work often resembles informal work, which has always existed, the ease of earning small amounts in platform markets will possibly lead to an increase of micro-earners, the sum of which could become an issue. For example, in most cases, informal workers are not liable for service quality and safety, they usually pay no taxes on small earnings, and do not contribute to- nor benefit from social security; although they might benefit from social security attached to another job.

A key question to answer in this context is: what (type of) threshold would be adequate in which sector to improve the protection of micro-earners, to minimise possible income tax loss, and to protect consumers, while allowing an appropriate amount of non-professional activity to flourish. Applying existing regulation to all providers, irrespective of the type and the amount of activity, might stifle innovation and supply in platform markets, notably when regulation was conceived for larger firms. 
Many providers in platform service markets work as independent contractors, although worker classification in different markets is subject to interpretation of existing law and debates. Some argue PW should be considered entrepreneurship, others argue it should be employment. From a theoretical point of view, a platform creates a market by matching providers and buyers. Platform operators are firms that employ like any other firm, in order to build, maintain, and improve the platform; however, it is less clear whether the operating firm should be considered to be the employer of individual providers selling in its market. In practice, some platform operators do more than simply providing a neutral market place, for example, by regulating the services provided in their market. Respectively, platforms like Hello Alfred (chores), Shyp (shipping), and Muchery (food delivery) are recognising providers in their markets as employees. The platforms mentioned in this paper before argue that they are not employers of the providers in their markets.

In many cases, the answer to the question whether individual providers in platform service markets should be independent workers or employees of the platform operator is not clear-cut. The main arguments about defining independent workers as employees are based on employment-test criteria, the most used ones of which in this debate are "control criteria". Depending on the platform operator's practices, control criteria might be pertinent, for example, when platform service providers have no choice but to follow specific instructions by the operator, or when the latter uses customer ratings to control or even dismiss providers. Other arguments are based on the "economic dependence" criterion, which might apply to some providers. Addressing this issue, Harris and Krueger (2015) have argued for introducing a "dependent contractor" definition, different versions of which exist, for example, in Italy, Germany, Canada, and France; others, however, question the effectiveness of such an additional category, notably based on the experience in the countries where it exists (De Stefano, 2016).

PW also raised attention for potentially precarious conditions of independent workers, notably as compared to full-time permanent employees. The latter usually bear little or no economic risk, have predictable income, social protection, health and pension insurances, and benefits, and therefore accept limited flexibility. In turn, theoretically, higher income, more autonomy, and flexibility should be key returns on the risks taken by entrepreneurs. Whether independent workers, many of which arguably cannot be called entrepreneurs, should bare the same economic risks as the latter should depend on the returns they can expect. While, in most cases, flexibility and autonomy are a reality of independent workers, they usually do not get the returns that successful entrepreneurs tend to get, and, in addition, are often accepting trade-offs, e.g. in terms of social security. In some countries, independent workers are covered by public insurance schemes; however, generally they tend to be worse off than full-time permanent employees, as discussed in section 4 (OECD, 2015c). This issue has not only emerged with PW, but is gaining new attention with the rise of platform markets.

\section{Multi-jobbing}

Several of the issues related to work in platform service markets gain in relevance when providers carry out multiple jobs, possibly in different markets. Individual providers working small amounts of time in different areas, cobbling together small incomes from different sources, might have no professional status for any, some, or only one of their activities, and thus the issues related to worker status could multiply. If the provider is an independent contractor, the question whether she should be considered as an employee or not might be posed for several of his or her activities. The trade-offs that independent contractors accept in many countries, as compared to standard workers, are likely to weigh even heavier for independent multi-jobbers who also spend significant time to search (accept) and manage different jobs, and as per the additional organisational efforts might have longer working hours and lower hourly wages. Finally, the fact that social security and benefits are usually linked to the job makes it more difficult, at least more complex, to ensure adequate and social security and benefits for workers engaged 
with multiple employers and clients. One response to this latter challenge, which is gaining increasing attention, is the proposal to link entitlements to individuals, rather than to jobs (Box 3).

\section{Box 3. Linking entitlements to individuals}

The approach to link entitlements to individuals, rather than to jobs, and to make them accumulative and portable, from one job to the next, is increasingly being discussed. One key objective of this approach is to avoid "job lock" by reducing the risk of individuals to lose their entitlements and to enhance flexibility in labour markets. One condition of the approach is continuous and multiple employer contributions. Such an approach could make independent work, including entrepreneurship, more accessible and attractive to many individuals.

Concrete proposals include the establishment of an individual or a "shared" security account, similar to US Social Security accounts, which could be established for all types of workers, regardless of their status. Automatic payroll deductions would aliment the individual account in proportion to the amount of work carried out for respective employers or clients. Keeping benefit systems linked to the worker status, and thus in separate systems, as is the case in most countries today, stifles flexibility, notably if job changes imply a change of status.

The US has a "multiemployer plan", which, however, is difficult to apply to PW, given that such a plan is usually the result of bargaining between unions and employers, and most independent workers, including in platform service markets, have no rights to organise and bargain (Hill, 2015). In France, a labour law, currently under discussion, might provide for a scheme that would link certain entitlements to the individual.

Source : Hill, 2015.

Multi-jobbers can further be distinguished into at least two groups, for one of which the issues discussed above might be less urgent. First is the group of individuals that is well-off, but motivated to earn some extra cash over platforms; second are individuals who offsets difficult economic situations by earning extra income via platforms. The Federal Reserve Bank of Boston (2015) finds that these two groups are clearly distinguishable and observes that providers with higher wages - who are likely to carry out PW to earn some extra cash - also tend to earn higher incomes over platforms. While for this group, the issues discussed above might seem less pressing, they are all the more relevant for those who carry out PW in order to sustain their living standard or to ensure subsistence levels. The more multi-jobbers depend on additional platform-based income, possibly cobbling together more than two income sources, the more urgent the issues discussed in relation to the provider's status.

\section{Provider competition and online reputation}

Competition among independent workers is not new, but competition in platform markets can reinforce existing dynamics and introduce new elements. For example, individual providers usually have to manage their public profile on online platforms, which often contains information on their performance, notably ratings and reviews by clients. Providers might also have to adjust to fluctuating prices on platforms that operate internationally (e.g. Upwork), or have to accept prices fixed by the platform operator (e.g. Uber). Clients can often choose, accept or reject providers, i.e. potentially discriminate, based on feedback from previous clients. Depending on the platform design, e.g. the matching model, each of these elements can play a more or less important role. Overall, competition among independent providers seems to be fiercer in platform markets than in traditional ones, in particular the larger the pool of providers, which is the case notably in international markets. Without any rules, such competition might engender a race to the bottom, which could affect providers' income and working conditions, and eventually their ability to compete. 
In most platform markets, clients rate and review their providers, which can provide useful information to other clients, but not necessarily always objective evaluations. Ratings and reviews are in most cases provided mutually by providers and by clients. Ratings are quantitative assessments, either in form of one aggregate score, e.g. many platforms are using a five-star rating, or split up in several ratings that evaluate different aspects of the service, e.g. cleanliness, location, truthfulness of information, and ease of communication in the case of individually provided accommodation. In addition, many platforms use qualitative reviews through which clients evaluate providers in their own words. Either one tool on its own, or both combined constitute the main information for clients to trust individual service providers. While ratings and reviews are effective tools that increase the amount of information in markets, they have potential shortcomings as well. For example, ratings and reviews can be false or manipulated, including by the platform, and might insufficiently reflect the possible evolution - improvement or deterioration - of service quality, given that scores usually show all-time averages. Averages can also be distorted by outliers, which in turn could be the result of very subjective client views, rather than an objective feedback on the service.

Currently, each platform administers its own reputation system, which means that providers have to build their reputation from scratch on each platform they use. Some argue that online reputation should be portable from one platform to another, and some suggest to aggregate online reputation from different platforms into one overall score or profile online. While this would indeed facilitate a provider who has built good reputation on one platform to enter other platform markets, it would also re-inforce the effects of negative online reputation, which a provider might have gained on one platform, justified or not, and create higher entry barriers for that individual in other platforms. Aggregating different ratings and reviews in a central accessible score or profile might increase the risk of unintended re-use of this information, for example by insurance companies and credit brokers, which could have unintended consequences. Given the large variety of rated and reviewed services, it is questionable whether the diverse possible reputations can be meaningfully combined in one. Even the transfer of reputation from one platform to another is not always necessarily meaningful. For example, a well-rated driver might not provide good care to elderly care or write good code. In short, while arguments for data portability might be valid for many cases, publically available online reputation might be a specific case that needs more differentiated consideration.

Finally, very little is known so far about other potential dynamics and effects of online reputation in platform markets. Given the generally powerful role of network effects in online markets, online reputation might be subject to similar dynamics as observed for platform dominated markets. For example, while many platforms create easy entry into service provision, the best paid segment of providers is likely to be composed of the "fittest" ones. This, in principle, might not be much different to offline markets, however, such individuals will have much larger leverage in online markets, e.g. by selling their potential globally.

\section{Fundamental principles and rights of workers}

The ways in which many platform markets currently function might raise issues with regards to fundamental rights of workers. The International Labour Organisation (ILO) identifies four categories of fundamental principles and rights at work: i) freedom of association and the effective recognition of the right to collective bargaining, ii) elimination of all forms of forced or compulsory labour, iii) effective abolition of child labour, and iv) elimination of discrimination in respect of employment and occupation (De Stefano, 2016). Some of these might be at risk in some platform markets.

Collective bargaining tends to be difficult to implement by independent workers in platform service markets, in particular in markets for digital services delivered over the Internet. Given that individual providers in platform markets often do not work for firms, a primary counterpart for social dialogue and collective bargaining by workers tends to be missing. This being said, in many countries, independent workers do not have the right to unionise. Even if they could, organisation among geographically dispersed 
participants in platform markets tends to be difficult; less so in markets for locally delivered services, but all the more in markets where services are transacted over the Internet. Collective organisation and bargaining in such markets is particularly difficult, because both providers and clients are likely to be dispersed in different countries and thus governed by different rules. In some countries and cities, some of these challenges have started to be addressed (Box 4).

\section{Box 4. Collective organisation of independent workers}

At national level, some unions are offering dedicated services to independent workers in platform markets. For example, the Freelancers Union in the US, with 275 thousand members, acts as an advocacy group and provides insurance schemes to its members, which include traditional freelancers and PW. However, the Freelancers Union has no bargaining rights and cannot engage in social dialogue. In Germany, the IG Metall union has launched a dedicated "crowdworker" platform, www.faircrowdwork.org, and another big German union, ver.di, is currently developing legal and support services tailored to PW. At city level, the Seattle City Council voted a bill in 2015 that will give Lyft and Uber drivers the right to unionise. Not least, some platforms are taking initiative as well. For example, in Germany, three crowdwork platforms have signed a Code of Conduct on paid crowdsourcing, supported by the German Crowdsourcing Association.

Sources : Freelancers Union, 2015b; Time, 2016; www.faircrowdwork.org; http://crowdsourcing-code.com/; www.crowdsourcingverband.de.

Forced labour and child labour could - possibly unknowingly - be exploited in platform markets. While to date no evidence exists on this issue, buyers of digital services delivered over the Internet have, in principle, difficulties to verify who produces the service and under which conditions. Simple click-work, for example, could be performed by children, who might even be systematically exploited by intermediaries that organise "click factories". More generally, workers could be forced into performing tasks in the production of a digital service. More studies are needed to better understand the risk of potential violation of the rights of an "invisible workforce" employed online.

Clients with a propensity to discriminate might also use the public information on providers to discriminate, for example, based on gender, ethnicity, skin colour, or social background. Again, evidence and studies on this issue are still rare, however the theoretical risk of discrimination is real. In addition to potential discrimination by employers, platforms also could discriminate. It might, for example, be argued some platforms' practices to refuse providers to work below a certain performance threshold, without recourse possibilities for providers, could be considered discrimination.

\section{Tasks and skills}

It is uncertain how many of the growing number of independent workers have the skills to thrive in platform service markets. Easy entry into PW might attract a number of individuals who lack the entrepreneurial and self-management skills to succeed in independent work. In contrast to well-educated and high-skilled entrepreneurs, simple workers, e.g. in handyman services, driving, or click-work, might have decided to enter PW motivated by short-term cash flow, but without properly accounting for the cost and risk they are taking on. Managing multiple jobs, building and maintaining online reputation, complying with potential liabilities, identifying and managing suitable health and pension schemes, covering holidays, maternity and sick leave, finding and carrying out training to upskill and build a career, to name just a few challenges, seems to go beyond traditional expectations associated with (independent) workers. If the latter do not have the skills to manage these responsibilities they currently have in most countries, they are unlikely to take advantage of perceived opportunities of PW. 
Services that involve mainly routine tasks and standardised outputs are arguably at higher risk to be automated. The schematic placement of different platform markets in Figure 2 along diagonal lines suggests that the more central a platform in the graphic, the higher the portion of routine tasks in the services traded over the respective platform, and thus the higher the risk of workers in these platform markets to lose their jobs to machines or artificial intelligence. The figure illustrates that a range of PW consists of fairly routine tasks, both manual and digital, even if another range of tasks in services traded over platforms include non-routine tasks. The threshold at which machines can take over some of the tasks currently performed by humans is likely to evolve and respectively, markets placed in Figure 2 would move more towards the outer corners. How fast this evolution is taking place in which area is difficult to predict at this point, but in several areas, platform markets are likely to contribute to accelerating automation potential to realise.

\section{Platforms as regulators and enforcers}

Platform operators have extensive possibilities to design and shape the functioning of their platforms, including through policies and regulation to govern interactions and behaviours in their markets. Starting with the design of the platform, an operator determines the rules for participation and interaction in its market. A commonly applied tool that regulates interaction and enforces behaviours on many platforms is mutual ratings and reviews, which provide public information on participants' behaviours. Some platforms provide additional behavioural information, such as providers' rate and speed of response to clients' requests. Among the most controversial regulating and enforcing platforms is Uber, which intervenes technically via the algorithm it designed for this purpose - on prices in its market, based on the proportion of demand and supply at any given moment. The platform also terminates drivers' accounts when the latters' ratings drop under a certain threshold. Other platforms offer insurance against accidents, e.g. Airbnb, or have implemented a minimum wage, such as TaskRabbit. These are only selected examples to illustrate the potential of platforms to regulate and enforce, which, in theory, is much bigger than current practices reflect.

\section{Box 5. Co-operation between platforms and regulators}

A few examples of co-operation between platforms and public authorities have emerged in recent years, notably between city administrations and platforms and in the area of taxation. For example, Airbnb has concluded agreements with a number of territories, collecting a variety of different types of taxes, including tourist tax (Amsterdam, NL; Paris and Chamonix-Mont-Blanc, France), lodging tax (Alabama, US), transit rental or accommodation tax (District of Columbia, US), tourist and discretionary sales tax (Florida, US), general excise tax (Hawaii and Oahu, US), sales tax (North Carolina; Rhode Island, US), hotel operators occupation tax (Illinois and Chicago, US), hotel and motel use and occupancy tax (Jersey City; Phoenix, Arizona, US), and service tax (India) among others. Uber has signed an MOU with the City of Vilnius to run a pilot in partnership with the City, which includes exchange of data to evaluate the company's impact in Vilnius.

In France, an article of the Finance Bill 2016 voted in December 2015 requires all platforms to provide an annual earnings statement (tax reminder) to active providers, in order to facilitate their tax filings (Airbnb had implemented this process before the law was passed). In Estonia, several platform operators are currently working together with tax authorities to find a solution for direct tax withholding via platforms and data exchange between the latter and public authorities to facilitate income tax collection.

Sources : Uber Newsroom, 2016; Airbnb, 2016b; Le Monde, 2015.

Beyond implementing their own and new regulation, some platforms have started co-operating with public regulators, to facilitate enforcement of existing regulation (Box 5). By design, public authorities have much less information on the interactions, including transactions, in online markets than platform 
operators who create and administer these markets and have the tools to closely monitor all activities on their platform. This gives authorities a strong incentive to co-operate with platform operators, including on enforcement, which is happening already in some countries, notably in the area of taxation.

\section{Privacy}

Despite some early examples of co-operation between platforms and public authorities, the more common practice is still non-co-operation. Platform operators have greater (technical) possibilities than any actor ever had in traditional markets to monitor and to manipulate activities in their markets. Most platforms are likely to collect vast amount of data and information, and usually claim to use these to improve services they provide to their market participants. Given that service improvements often imply changes in the design of the platform, as subtle as they may be, they tend to influence the behaviour of market participants. Furthermore, one could expect such improvements to nudge participants' behaviours in ways that benefit the commercial interests of the platform operator. It is unsure when such interests overlap with the interests of individuals and with public interests. Data on activities in platform markets could in fact be collected and used in the interest of both individuals and the public, however, making all such data publically available would also affect the core asset and the competitiveness of platform operators. The current situation in most cases calls for more work to be done on this potential tension and, e.g. to what extent data-sharing between platform operators and public authorities can improve the current situation.

Publically available information on providers might be used for unintended purposes. The type and amount of information displayed publically by providers in many platform markets goes beyond any information that was ever publically available on individuals. For example, uploading photos of a private apartment together with a personal profile and picture on Airbnb provides fairly deep insights into the private sphere of individuals, accessible for anyone browsing through Airbnb. In order for on-demand service markets, including short-term rental, to be liquid and efficient, a maximum amount of information would need to be available online, including on individual's assets, time and skills. In other words, the privacy of individuals that are active in platform service markets, notably on platforms that enable the "sharing" of personal assets, might be compromised through such activities. This becomes an issue in particular when publically available personal information, including ratings and reviews and other behavioural data, can be directly re-used for different purposes than selling or buying in a specific market, for example, by credit agencies or insurance companies; or if such data is sold to third parties that also could make use of such data way beyond its initially intended purpose.

\section{Assessment of regulatory frameworks}

The emergence of platforms in the different markets discussed above has shaken up some of these markets and has sparked reaction in many jurisdictions, including calls for new regulation. While some of the services transacted in platform markets differ from traditional offerings, and platform markets are affecting the production of services, as discussed in section 3, many of the policy issues discussed above are neither new nor exclusively relevant for PW. Some old issues gain new attention and possibly importance in the context of PW, such as taxation of informal and small economic activities, worker classification, multi-jobbing differences between standard and non-standard workers, and privacy in digital environments. Other issues are genuinely new and might require consideration for new approaches. This may include the review of legislation and regulation, such as those related to the status, rights and responsibilities of market participants, as well as of platform operators, and those related to data collection and use. Another issue that may merit closer consideration is the possible co-operation between platforms and regulators. A good starting point for further assessing any of these issues would be to clarify how existing rules apply to the emerging practices in platform markets. 
If existing rules are not applicable to new practices, the assessment of the potential need for new rules should be guided by a clear objective(s). The hastened regulatory responses that can be observed in some countries and cities in response to the emergence of platforms often seem to be driven rather by specific interests or by perceived public opinion than by objectives that are in the public's interest. Figure 15, adopted from a discussion paper by the Netherlands EU Presidency, illustrates some basic steps that can help assess a potential need for action, including regulation. Such an assessment would furthermore benefit from systematically taking into account both the opportunities and the challenges that should be identified based on evidence and analysis of the issue(s) in question. Table 9 summarises the opportunities and challenges identified in this paper in relation to new forms of work in platform service markets and in relation to other forms of non-standard work. Given that much of the developments in platform markets are happening fast, hastened regulation or deregulation, based on weak evidence, might result in unintended consequences rather than achieve the desired objective(s).

Table 9. Opportunities and challenges of new forms of work and other non-standard work

\begin{tabular}{|c|c|}
\hline Opportunities & Challenges \\
\hline \multicolumn{2}{|c|}{ Labour markets } \\
\hline Flexible access to work and income opportunities & Non-standard work, small jobs, micro tasks \\
\hline Possible inclusion of marginal groups in labour force & Potential 'race to the bottom' and wage penalty \\
\hline Low barriers to entry and exit of work & Less employer-sponsored training of workers \\
\hline \multicolumn{2}{|c|}{ Working conditions } \\
\hline Flexible working time (and space for digital services) & Job insecurity, higher unemployment risk \\
\hline Autonomous work organisation & Less or more expensive social protection and benefits \\
\hline Potential productivity gains & Potential stress of self-management and social isolation \\
\hline
\end{tabular}

Source: Adapted from Eurofund, 2015

Many of the emerging issues related to platform markets cannot be addressed with one-size-fits-all solutions, but different rules in different jurisdictions should be harmonised to the extent possible. Many of the services delivered physically in local platform-based markets, such as accommodation and transportation, are subject to sub-national regulation, which is rarely the same in different countries and can also differ across regions and cities within one country. Different jurisdictions might need to find individual solutions for emerging issues and would do well to identify other jurisdictions that face the same issues under similar conditions. In addition, platforms that operate in different urban and different domestic markets might actually not be used in the same in all places, as demonstrated for Uber above. While different approaches might be necessary in different jurisdictions, harmonised rules across jurisdictions, for example within the United States or within Europe, will be an important condition to foster the opportunities that emerge with platforms markets. 


\section{Figure 15. Assessing the need for regulation}

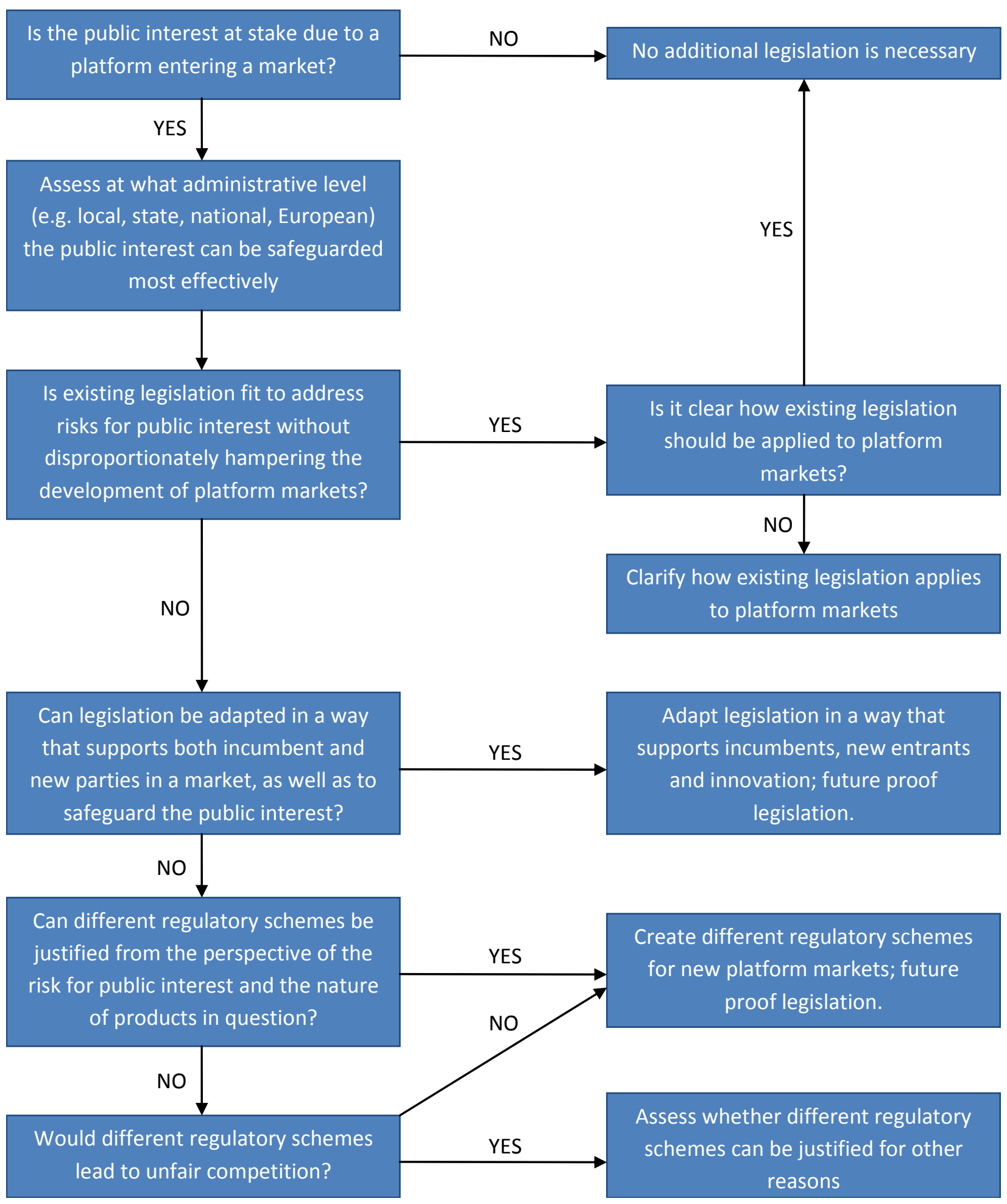

Source: adapted from Netherlands EU Presidency, 2016. 


\section{Measurement needs}

The evidence and analysis of the rise of online platforms, the developments in of selected platform markets, and the trends in non-standard work in OECD labour markets presented in this paper only provide a snapshot of growing platform markets. Better data is needed to provide a more comprehensive picture and to enable more in-depth analysis of these developments, for example, data on the size and growth of the labour force in platform markets, working patterns, multi-jobbing, the status of providers, and opportunities and challenges perceived by market participants. In the short run, dedicated surveys at national level can produce relevant snapshots. For example, Uni Europa and the University of Hertfordshire carried out a survey on the "Size of the UK's 'Gig Economy'", which was replicated by Sweden and might be done in other countries as well (UniEuropa, 2016). Shortcomings of such surveys include potential confusion around definitions (ONS, 2016) and limitations in providing comparable data across the OECD.

Some OECD countries have started considering the need to expand their data collection to measure the growth and effects of platform markets. For example, the European commission announced to monitoring evolving regulatory environments and economic and business developments related to online platforms as part of a European agenda for the "collaborative economy"; Denmark is working on the introduction of new questions in existing national surveys and has carried out a first survey on the demand and supply of platform-based transport and accommodation services in Denmark: the US announced to revive the BLS's "Contingent Work Supplement" supplemented to its Current Population Survey in 2017; Canada added questions to its Labour Force Survey to better capture householder behaviours; and Eurostat is including questions on platform-based accommodation and transport services in its next survey on ICT usage by households and individuals. These are first steps, but more systematic and co-ordinated efforts are needed to improve data collection on platform markets and on their effects.

Given that many of the service providers in platform markets are individuals, data collection should focus on individuals, not only on firms and households. Countries would benefit from identifying possibilities to introduce relevant questions in existing surveys that allow individual level data collection, such as Labour Force or Time Use surveys. Such questions may touch upon specific characteristics of work that can be relevant for PW and any other NSW. For example, the UK Labour Force Survey asks whether or not respondents have more than one job, and how many hours are worked in additional jobs. More detail would also be needed on the nature of combined jobs and sources of income that might not necessarily be considered as jobs by all respondents (Bean, 2016). Collecting data with regular surveys in different areas would allow the measurement of multiple effects that online platforms can have over time.

The analysis of some specific aspects, for example, the functioning of online reputation in platform markets, requires data that is less likely to be collected by public agencies. Such data, however, are accumulating on the servers of many platform operators. While the latter are usually not sharing much data, except for targeted communication purposes and in selected partnerships, more collaboration between the platform operators, research institutions, international organisations and governments would be desirable to build evidence that would allow analysing more specific dynamics and effects of platform markets. More work is needed to identify forms of collaboration that can be in the interest of both platform operators and other parties.

Beyond data related to PW, additional data needs to be collected to measure and analyse the multiple dynamics and effects of platform markets. For example, better data is needed to analyse i) effects of online platforms on macro economic indicators, productivity, the environment, inequality, and well-being, ii) competition among platforms, competition between platforms and more traditional players, as well as competition among providers within platform markets, and iii) consumer protection and privacy related issues in the context of platforms creating and entering markets. 


\section{REFERENCES}

Agrawal, A., Horton, J., Lacetera, N. and E. Lyons (2015), "Digitization and the Contract Labour Market a Research Agenda", Chapter in: Goldfarb, A., Greenstein, S., and C. Tucker, [Edit.] (2015), Economic Analysis of the Digital Economy, pp. 219 - 250, www.nber.org/chapters/c12988, accessed on 3 November 2015.

Airbnb (2016a), "L'impact économique de Airbnb en France", Airbnb blog, http://blog.airbnb.com/limpacteconomique-dairbnb-en-france/, accessed 25 May 2016.

Airbnb (2016b), "In what areas is Occupancy Tax Collection and Remittance by Airbnb available?", Airbnb website, www.airbnb.com/help/article/653/in-what-areas-is-occupancy-tax-collection-andremittance-by-airbnb-available, accessed 08 March 2016.Airbnb (2015a), "About us", Airbnb website, www.airbnb.com/about/about-us, accessed on 3 November 2015.

Airbnb (2015a), "About us", Airbnb website, www.airbnb.com/about/about-us, accessed on 3 November 2015.

Airbnb (2015b), "The Future of the Sharing \& Digital Economy", Presentation by Olivier Grémillion, Harvard Club of France, Boston Consulting Group, Paris, France.

Airbnb (2015c), "Airbnb data for OECD study", internal data, Paris, France.

Airbnb (2015d), "Airbnb takes care of business", Airbnb website, www.airbnb.com/business/signup, accessed on 3 November 2015.

Arntz, M., T. Gregory and U. Zierahn (2016), “The Risk of Automation for Jobs in OECD Countries: A Comparative Analysis”, OECD Social, Employment and Migration Working Papers, No. 189, OECD Publishing, Paris. http://dx.doi.org/10.1787/5jlz9h56dvq7-en.

Bean, S.C. (2016), "Independent Review of UK Economic Statistics", HM Treasury, Cabinet Office, The Rt Hon Matt Hancock MP and The Rt Hon George Osborne MP, www.gov.uk/government/publications/independent-review-of-uk-economic-statistics-final-report, accessed 15 June 2016.

Bloomberg (2015), "The Sharing Economy", Bloomberg Briefs, June 2015, http://newsletters.briefs.blpprofessional.com/repo/uploadsb/pdf/false_false/bloombergbriefs/4vz1acb gfrxz8uwan9_0_1019.pdf, accessed on 3 November 2015.

BLS (US Bureau of Labour Statistics) (2015a), "Economic News Release: Employment status of the civilian population by sex and age", BLS website, http://www.bls.gov/news.release/empsit.t01.htm, accessed on 3 November 2015.

BLS (2015b), "Labor Force Statistics (CPS), Table A-9 (Historical Data), www.bls.gov/webapps/legacy/cpsatab9.htm, accessed 2 Marched 2016.

Brynjolfsson, E. and A. McAfee (2008), "Scale without Mass: Business Process Replication and Industry Dynamics", http://ebusiness.mit.edu/research/papers/2008.09_Brynjolfsson_McAfee_Sorell_Zhu_Scale\%20Wit hout\%20Mass_285.pdf, accessed 21 November 2015. 
CGE (Conseil Général de l'Économie, de l'Industrie, de l'Énergie et des Technologies) (2015), "Baromètre du Numérique", Ministre de l'Économie, de l'Industrie et du Numérique, www.arcep.fr/uploads/tx_gspublication/CREDOC-Rapport-enquete-diffusion-TIC-France_CGEARCEP_nov2015.pdf.

Coase, R. H. (1937), "The Nature of the Firm", Economica, New Series, Vol. 4, No. 16 (Nov., 1937), pp. 386-405, www.jstor.org/stable/2626876?seq=1\#page_scan_tab_contents, accessed on 3 November 2015.

Coase, R.H. (1960), "The problem of social cost", The Journal of Law and Economics, Vol. III, 1960, pp. 1-44, http://onlinelibrary.wiley.com/doi/10.1002/sres.3850090105/abstract, accessed on 3 November 2015.

Davis, J. (2015), "Capital markets and job creation in the 21st century", The Brookings Institution, www.brookings.edu/ /media/research/files/papers/2015/12/30-21st-century-job-creationdavis/capital_markets.pdf.

Deloitte (2016), "Economic effects of ridesharing in Australia", Uber and Deloitte Access Economics, www2.deloitte.com/content/dam/Deloitte/au/Documents/Economics/deloitte-au-economic-effectsridesharing-australia-010216.pdf.

DESTATIS (Statistisches Bundesamt) (2014), "Private Konsumausgaben - Deutschland", destatis website, www.destatis.de/DE/ZahlenFakten/GesellschaftStaat/EinkommenKonsumLebensbedingungen/Kons umausgaben/Tabellen/PrivateKonsumausgaben_D.html, accessed on 3 November 2015.

DOL (U.S. Department of Labour) (2016), "Innovation and the Contingent Workforce", blogpost by Secretary Tom Perez, January 25, https://blog.dol.gov/2016/01/25/innovation-and-the-contingentworkforce/, accessed 02 March 2016.

Donovan et al. (2016), "What Does the Gig Economy Mean for Workers?", CRS Report prepared for Members and Committees of Congress, Congressional Research Service, www.fas.org/sgp/crs/misc/R44365.pdf.

De Groen, W.P. et al. (2016), "The Digital Market for Local Services: A one-night stand for workers? An example from the on-demand economy", European Union, doi:10.2788/536883.

De Stefano, V. (2016), The rise of the «just-in-time workforce»: On-demand work, crowdwork and labour protection in the «gig-economy», International Labour Office, Geneva, www.ilo.org/wcmsp5/groups/public/---ed_protect/---protrav/--travail/documents/publication/wcms_443267.pdf.

EC (European Commission) (2016), "Flash Eurobarometer 438. Collaborative Platforms", EC website, http://ec.europa.eu/COMMFrontOffice/PublicOpinion/index.cfm/Survey/getSurveyDetail/instrumen ts/FLASH/surveyKy/2112, accessed 03 June 2016.

Eurofound (2015), New forms of employment, Publications Office of the European Union, Luxembourg.

Federal Reserve Bank of Boston (2015), "Changing Patterns in Informal Work Participation in the United States 2013-2015", Current Policy Perspectives Papers, www.bostonfed.org/economic/currentpolicy-perspectives/2015/cpp1510.pdf.

Fortune (2015a), "The Unicorn List", Fortune.com, http://fortune.com/unicorns/, accessed on 3 November 2015.

Fortune (2015b), "Here’s how Airbnb justifies its eye-popping \$24 billion valuation", Fortune, http://fortune.com/2015/06/17/airbnb-valuation-revenue/, accessed on 3 November 2015.

Freelancer (2016a), "Freelancer Limited - FY 2015 Fully Year Results Presentation", www.freelancer.com/investor, accessed 15 June 2015. 
Freelancer (2016b), "Freelancer data for OECD study", internal data, Paris, France.

Freelancers Union (2015a), "Freelancing in America: A National Survey of the New Workforce", Freelancers Union \& Elance-oDesk, https://fu-web-storageprod.s3.amazonaws.com/content/filer_public/7c/45/7c457488-0740-4bc4-ae450aa60daac531/freelancinginamerica_report.pdf, accessed on 3 November 2015.

Freelancers Union (2015b), "About Us", Freelancers Union website, www.freelancersunion.org/about/, accessed on 3 November 2015.

Galperin H., Viecens, F. and Greppi C. (2015), "Discrimination in Online Contracting: Evidence from Latin America", Diálogo Regional sobre Sociedad de la Información, Lima, www.google.fr/webhp?sourceid=chrome-instant\&ion=1\&espv=2\&ie=UTF-8\#q=Galperin-2015Discrimination-in-online-contracting_evidence-from-LA, accessed on 3 November 2015.

GAO (US Government Accountability Office) (2015), "Contingent Workforce: Size, Characteristics, Earnings, and Benefits", www.gao.gov/assets/670/669766.pdf, 21 November 2015.

GCD (Group Caisse de Depot) (2015), "Baromètre de la confiance des Français dans le numérique", Rapport d'étude, internal document.

Görg, H., L. Killen and F. Ruane (1998), “Non-Standard Employment in Irish Manufacturing: Do Firm Characteristics Matter?”, Labour, Vol. 12, No. 4, pp. 675- 699.

Hall, J. and A. Krueger, (2015), "An Analysis of the Labor Market for Uber's Driver-Partners in the United States", Working Papers, Princeton University, Industrial Relations Section, No 587, http://dataspace.princeton.edu/jspui/handle/88435/dsp010z708z67d, accessed on 3 November 2015.

Harris, S. D. and A. Krueger (2015), "A Proposal for Modernizing Labor Laws for Twenty-First-Century Work: The "Independent Worker"", Discussion Paper, The Hamilton Project, http://www.hamiltonproject.org/assets/files/modernizing_labor_laws_for_twenty_first_century_wor k_krueger_harris.pdf.

Hill, S. (2015), "New Economy, new social contract; a Plan for a Safety Net in a Multi-Employer World", New America, https://static.newamerica.org/attachments/4395-new-economy-new-socialcontract/New\%20Economy,\%20Social\%20Contract_UpdatedFinal.34c973248e6946d0af17116fbd6 bb79e.pdf.

Houseman, S.N. and M. Osawa (2003), "Introduction to Nonstandard Work in Developed Economies", W.E. Upjohn Institute for Employment Research, Kalamazoo, United States, pp. 1-14.

Ifop (2016), ENQUÊTE AUPRÈS DES PARTENAIRES CHAUFFEURS ACTIFS SUR UBER, Ifop and Uber, www.ifop.com/?option=com_publication\&type=poll\&id=3277, accessed 22 February 2016.

Inc. (2015), "How Peer to Peer Worker Services Are Changing the Debate on Wages", Inc. website, www.inc.com/jeremy-quittner/freelance-sites-add-worker-protections-like-higher-minimumwage.html, accessed on 3 November 2015.

Intuit (2015), "Intuit Forecast", businesswire, www.businesswire.com/news/home/20150813005317/en/, accessed on 3 November 2015.

ITF (2014), “Urban mobility: System upgrade”, International Transport Forum and Corporate Partnership Board, http://internationaltransportforum.org/cpb/pdf/urbanmobility.pdf, accessed 30 October 2015.

JPM (JPMorgan Chase\&Co. Institue) (2016), "Paychecks, Paydays, and the Online Platform Economy", www.jpmorganchase.com/corporate/institute/document/jpmc-institute-volatility-2-report.pdf.

Kalleberg, A.L (2000), "Nonstandard Employment Relations: Part-time, Temporary and Contract Work”, Annual Review of Sociology, Vol. 26, pp. 341-365. 
Kalleberg, A.L., E. Rasell, N. Cassirer, B.F. Reskin, K. Hudson, D. Webster, E. Appelbaum and R.M. Spalter-Roth (1997), Nonstandard Work, Substandard Jobs: Flexible Work Arrangements in the U.S., Economic Policy Institute and Women's Research and Education Institute, Washington, D.C.

KPCB (2015), "Internet Trends, Mary Meeker Presentation, May 27 2015, www.kpcb.com/internet-trends, accessed on 3 November 2015.

Landier, A., Szomoru, D. and D. Thesmar (2016), "Working in the on-demand economy: an analysis of uber driver-partners in France", Uber blog post, https://drive.google.com/a/uber.com/file/d/0B1s08BdVqCgrZWZrQnVWNUFPNFE/view?pref=2\& pli=1, accessed 9 March 2016

Le Monde (2015), "Airbnb, Drivy : que change l'amendement sur l'information fiscale ?", Le Monde, Économie, 15.12.2015, www.lemonde.fr/economie/article/2015/12/15/airbnb-drivy-que-change-lamendement-sur-l-information-fiscale_4832089_3234.html, accessed 8 March 2016.

Leschke, J. (2011), “Labour Market Developments in the Light of the Crisis and the Europe 2020 Strategy”, EU Anticipedia.

MBO (2015), "Independent Workers and the On-Demand Economy", MBO Partners, http://info.mbopartners.com/rs/mbo/images/On-Demand-Economy-2014.pdf, accessed on 3 November 2015.

MGI (McKinsey Global Institute) (2015), "A labor market that works: connecting talent with opportunity in the digital age", www.mckinsey.com/insights/employment_and_growth/connecting_talent_with_opportunity_in_the _digital_age, accessed on 3 November 2015.

Miller, J. and M. Miller (2012), "The Rise of the Supertemp", Harvard Business Review, https://hbr.org/2012/05/the-rise-of-the-supertemp, accessed 9 March 2016.

NESTA (2015), "Towards an Index of the Collaborative Economy", NESTA, www.nesta.org.uk/sites/default/files/an_index_of_collaborative_activity_-.pdf.

Netherlands EU Presidency (2016), "Harnessing the potential of the collaborative economy", https://gallery.mailchimp.com/6794b67601df637faf34bd5c6/files/Presidency_discussion_paper_Lun ch_debate_Collaborative_economy_2_1_.pdf.

Nubelo (2014), "Primer informe regional sobre la industria del trabajo 3.0", Nubelo website, http://landing.nubelo.com/informe-trabajo-trespuntocero-f/, accessed on 3 November 2015.

ONS (Office of National Statistics) (2016), "The feasibility of measuring the sharing economy", UK Government website, www.gov.uk/government/statistics/the-feasibility-of-measuring-the-sharingeconomy, accessed 13 April 2016.

OECD (2015a), "OECD Better Life Index - Housing", OECD Better Life Index, www.oecdbetterlifeindex.org/topics/housing/, accessed on 3 November 2015.

OECD (2015b), "OECD metropolitan databse", OECD.Stat, https://stats.oecd.org/Index.aspx?DataSetCode=CITIES, accessed on 3 November 2015.

OECD (2015c), In It Together: Why Less Inequality Benefits All, OECD Publishing, Paris. http://dx.doi.org/10.1787/9789264235120-en.

OECD (2015d), OECD Employment Outlook 2015, OECD Publishing, Paris. http://dx.doi.org/10.1787/empl_outlook-2015-en.

OECD (2014), OECD Employment Outlook 2014, OECD Publishing, Paris. http://dx.doi.org/10.1787/empl_outlook-2014-en. 
OECD (2000), OECD Employment Outlook, Chapter 5: “The Partial Renaissance of Self Employment”, OECD Publishing, Paris, http://dx.doi.org/10.1787/empl_outlook-2000-en.

Pew (Pew Research Center) (2016), "Shared, Collaborative and On Demand: The New Digital Economy”, www.pewinternet.org/2016/05/19/the-new-digital-economy/, accessed 23 May 2016.

Plouffe, D. (2015), "Uber and the American Worker", Uber website, https://newsroom.uber.com/1776/, accessed 07 March 2016.

Reuters (2015), "Uber seen reaching $\$ 10.8$ billion in bookings in 2015: fundraising presentation", Reuters, www.reuters.com/article/2015/08/21/us-uber-tech-fundraising-idUSKCN0QQ0G320150821, accessed on 3 November 2015.

RFS (Request for Startup) (2015), "2015 1099 Economy Workforce Report", RFS website, www.requestsforstartups.com/survey, accessed on 3 November 2015.

Romei (2015), "The New World of Work: A changing landscape", Financial Times, 4 August 2015.

Schmidt, S. (2016), "From scarcity to abundance: growing the overall pie", Uber Under the Hood blog, 12 January 2016, https://medium.com/@UberPubPolicy/from-scarcity-to-abundance-growing-theoverall-pie-by-sophie-schmidt-a2e5a24bbc71\#.19sk1x2ni, accessed 08 March 2016.

Staffing Industry (2015), "The Human Cloud Landscape", staffingindustry.com, www.staffingindustry.com/row/Research-Publications/Research-Topics/Asia-Pacific-LatinAmerica-Middle-East-Africa/The-Human-Cloud-Landscape, accessed on 3 November 2015.

Statista (2015), "Average domestic business trip length in Great Britain from 2010 to 2015 (in days)", statista website, www.statista.com/statistics/297528/average-domestic-business-trip-length-in-greatbritain/, accessed on 23 November 2015.

Time (2016), " See How Big the Gig Economy Really Is", Time website, http://time.com/4169532/sharingeconomy-poll/, accessed 07 March 2016.

Uber (2015), "Diving deeper on how Uber improves access to transit", Uber Under the Hood, 16 December 2015, https://medium.com/@UberPubPolicy/diving-deeper-on-how-uber-improves-access-to-transit574d3af18d7b\#.qq3m1mr4y, accessed 8 March 2016.

Uber (2016a), "New Survey: Drivers Choose Uber for its Flexibility and Convenience", Uber News Room, https://newsroom.uber.com/driver-partner-survey/, accessed 8 March 2016.

Uber (2016b), "An Open Letter to the Mayor on Congestion in London", Uber Newsroom, https://newsroom.uber.com/uk/open-letter/, accessed 8 March 2016.

UK-BIS (Department for Business, Innovation \& Skills) (2015), " Sharing economy: government response to the independent review", UK-BIS website, www.gov.uk/government/publications/sharingeconomy-government-response-to-the-independent-review, accessed on 3 November 2015.

Uni Europa (2016), "Size of Sweden’s ‘Gig Economy’ revealed for the first time - around 700,000 crowd workers in Sweden", Uni Europa website, www.uni-europa.org/wpcontent/uploads/2016/03/Swedens-digital-economy.pdf.

University of Hertfordshire (2016), Size of the UK’s “Gig Economy”, Crowd Working Survey, February 2016, http://www.feps-europe.eu/assets/a82bcd12-fb97-43a6-9346-24242695a183/crowd-workingsurveypdf.pdf.

Upwork (2015a), "Online work report 2014", Upwork website, http://elance-odesk.com/online-workreport-global, accessed on 3 November 2015.

Upwork (2015b), "Upwork Payroll Agreement", Upwork website, www.upwork.com/legal/upworkpayroll-agreement/, accessed on 3 November 2015. 
Upwork (2016a), "About us. Creating an online workplace for the world", Upwork website, www.upwork.com/about/, accessed 8 March 2016.

Upwork (2016b), "Find the World's best Statistics Freelancer", Upwork website, www.upwork.com/hire/statistics-freelancers/, accessed 8 March 2016.

USCB (U.S. Census Bureau) (2015), "Nonemployer Statistics", USCB website, www.census.gov/econ/nonemployer/index.html, accessed 02 March 2015.

Wenger, J. (2003), “Share of Workers in Nonstandard Jobs Declines”, Economic Policy Institute Briefing Paper, No. 137.

Youpijob (2015), "Youpijob data for OECD study", confidential data, Paris, France. 